\title{
Quinizarin derivatives as photoinitiators for free-radical and cationic photopolymerizations in the visible spectral range
}

Pauline Sautrot-Ba, ${ }^{1}$ Steffen Jockusch, ${ }^{2}$ Jean-Pierre Malval, ${ }^{3}$ Vlasta Brezova, ${ }^{4}$ Michael Rivard, ${ }^{1}$ Samir Abbad-Andaloussi, ${ }^{5}$ Agata Blacha-Grzechnik, ${ }^{6}$ Davy-Louis Versace $* 1$

${ }^{1}$ Institut de Chimie et des Matériaux Paris-Est (ICMPE) - UMR-CNRS 7182 Equipe Systèmes Polymères Complexes (SPC) 2-8, rue Henri Dunant, 94320 Thiais, France.

${ }^{2}$ Department of Chemistry, Columbia University, 3000 Broadway, New York, NY 10027, United States.

${ }^{3}$ Institut de Chimie des Matériaux de Mulhouse (IS2M)-UMR 7361, 15 rue Jean Starcky - BP 2488, 68057 Mulhouse cedex, France.

${ }^{4}$ Slovak University of Technology in Bratislava, Institute of Physical Chemistry and Chemical Physics, Department of Physical Chemistry, Radlinského 9, SK-812 37 Bratislava, Slovak Republic.

${ }^{5}$ Université Paris-Est Créteil (UPEC), Laboratoire Eau, Environnement, Systèmes Urbains (LEESU), UMR-MA 102, 61 avenue Général de Gaulle, 94010 Créteil Cedex, France.

${ }^{6}$ Faculty of Chemistry, Silesian University of Technology, Strzody 9, 44-100 Gliwice, Poland

*Corresponding author: versace@icmpe.cnrs.fr 
A
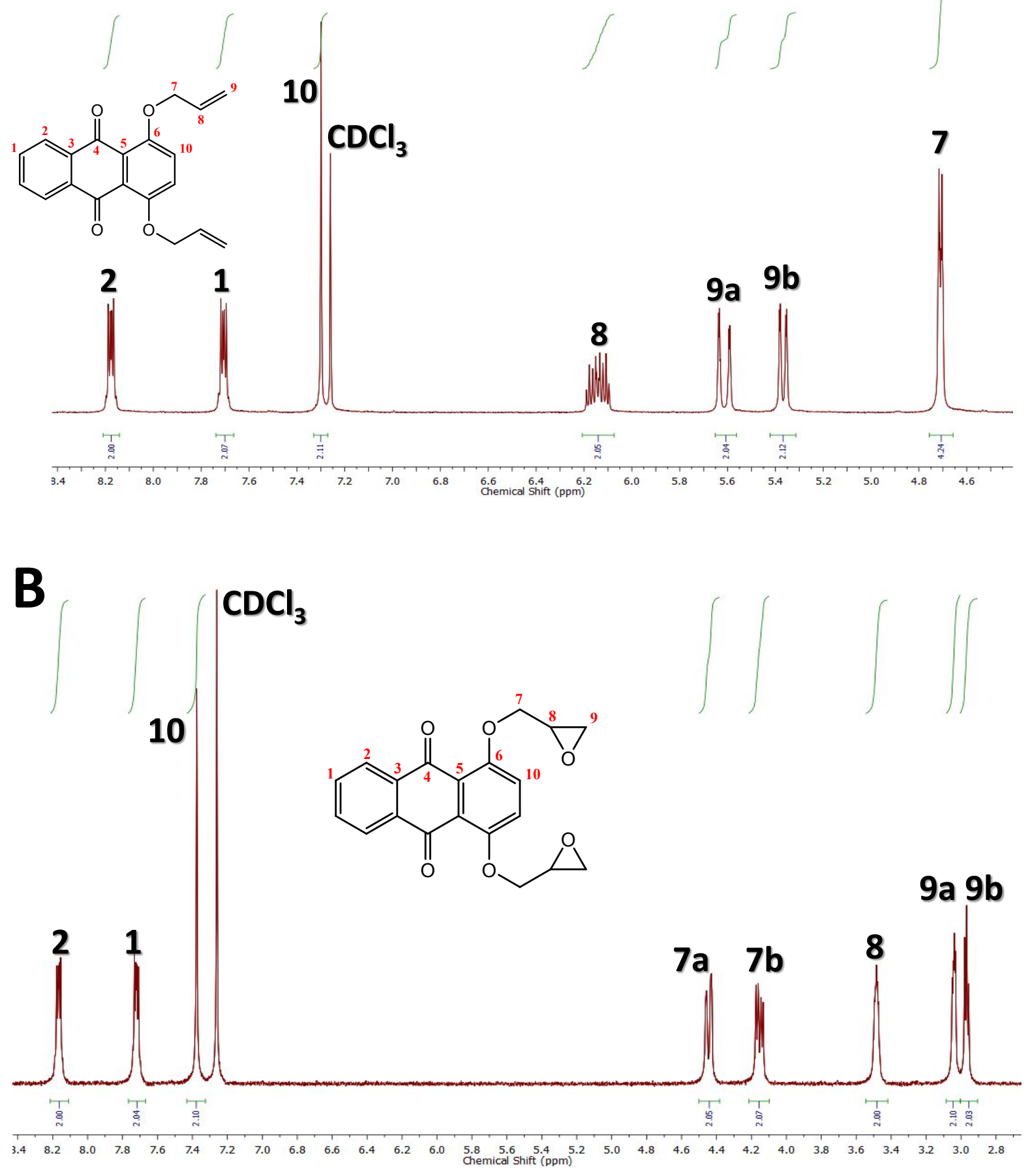

Figure S1. ${ }^{1} \mathrm{H}$ NMR spectra of A) $\mathbf{Q A}$ and B) $\mathbf{Q E}$ in $\mathrm{CDCl}_{3}$ 

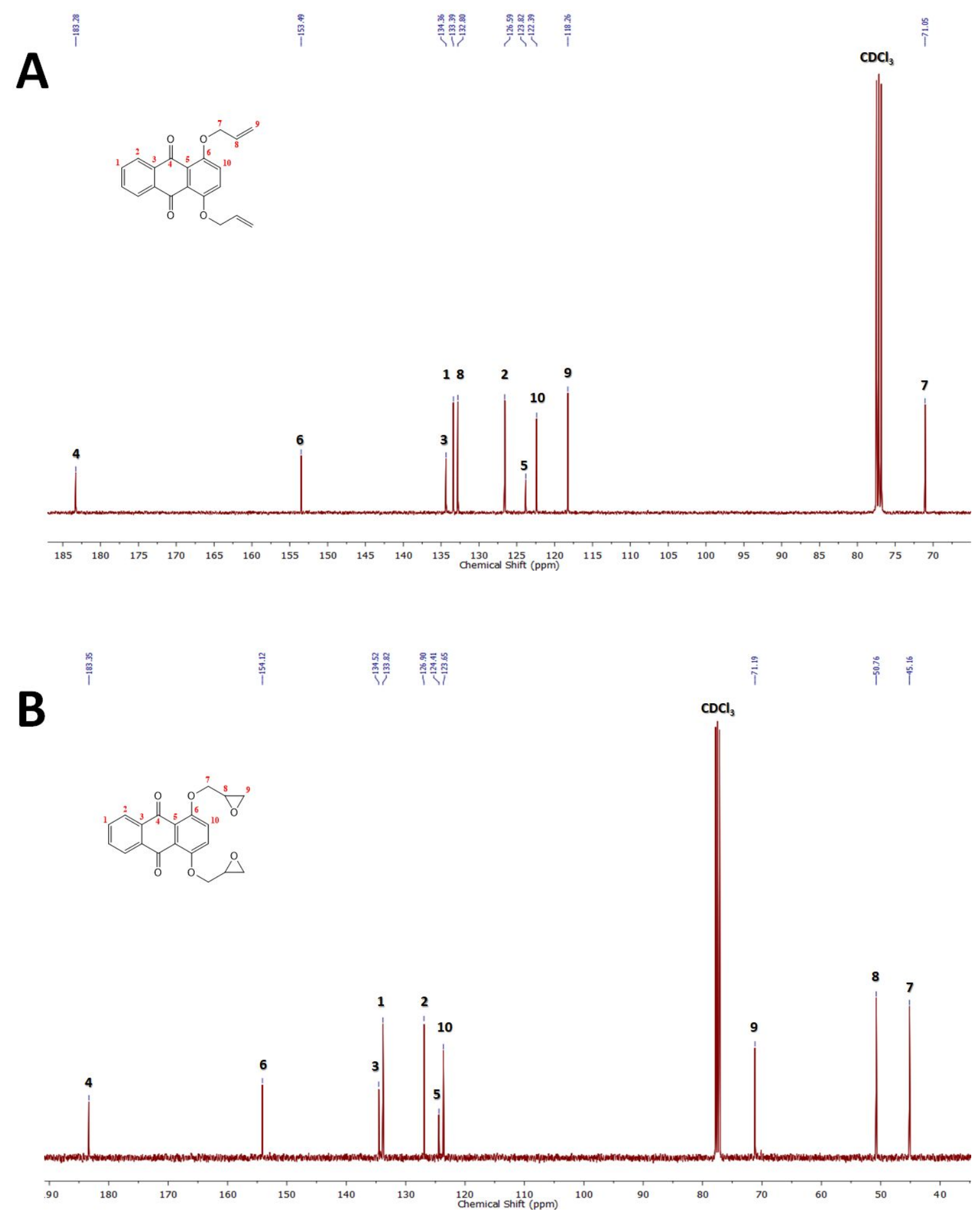

Figure S2. ${ }^{13} \mathrm{C}$ NMR spectra of A) $\mathbf{Q A}$ and B) $\mathbf{Q E}$ in $\mathrm{CDCl}_{3}$ 
A

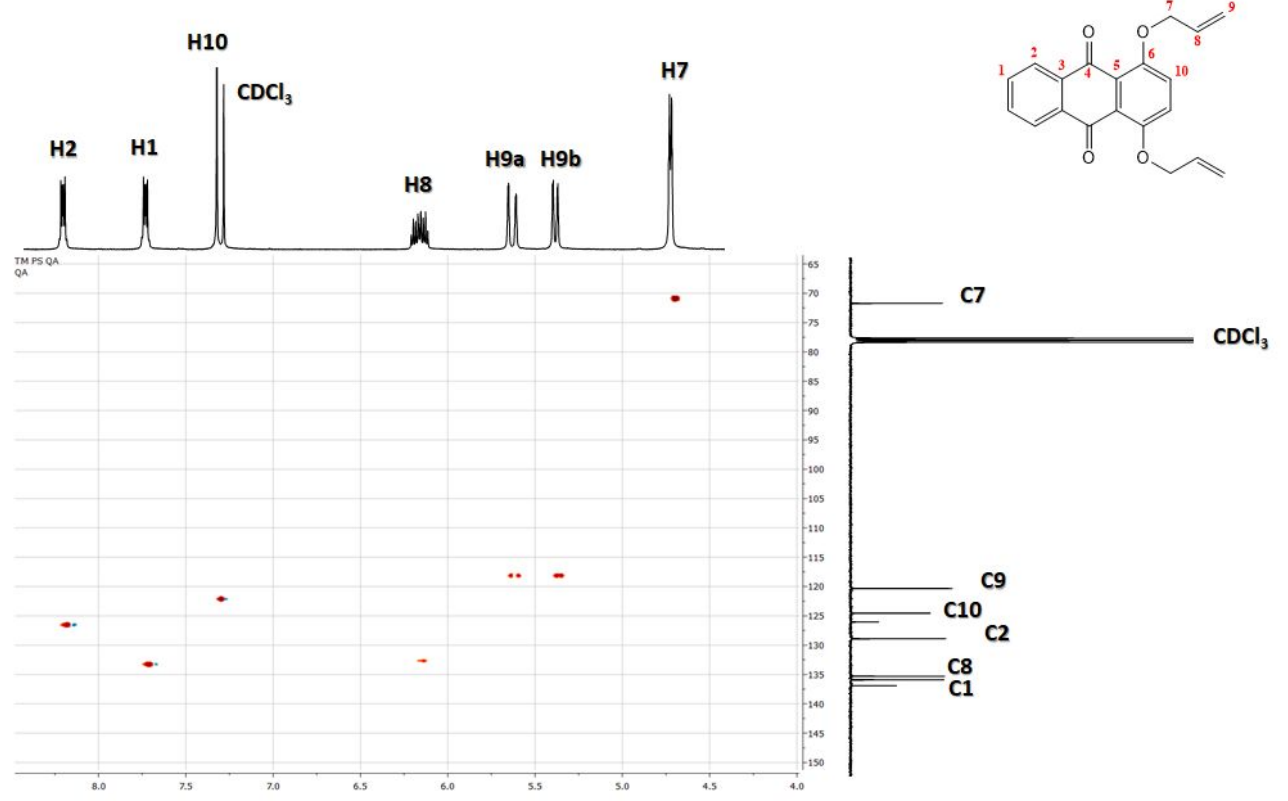

B

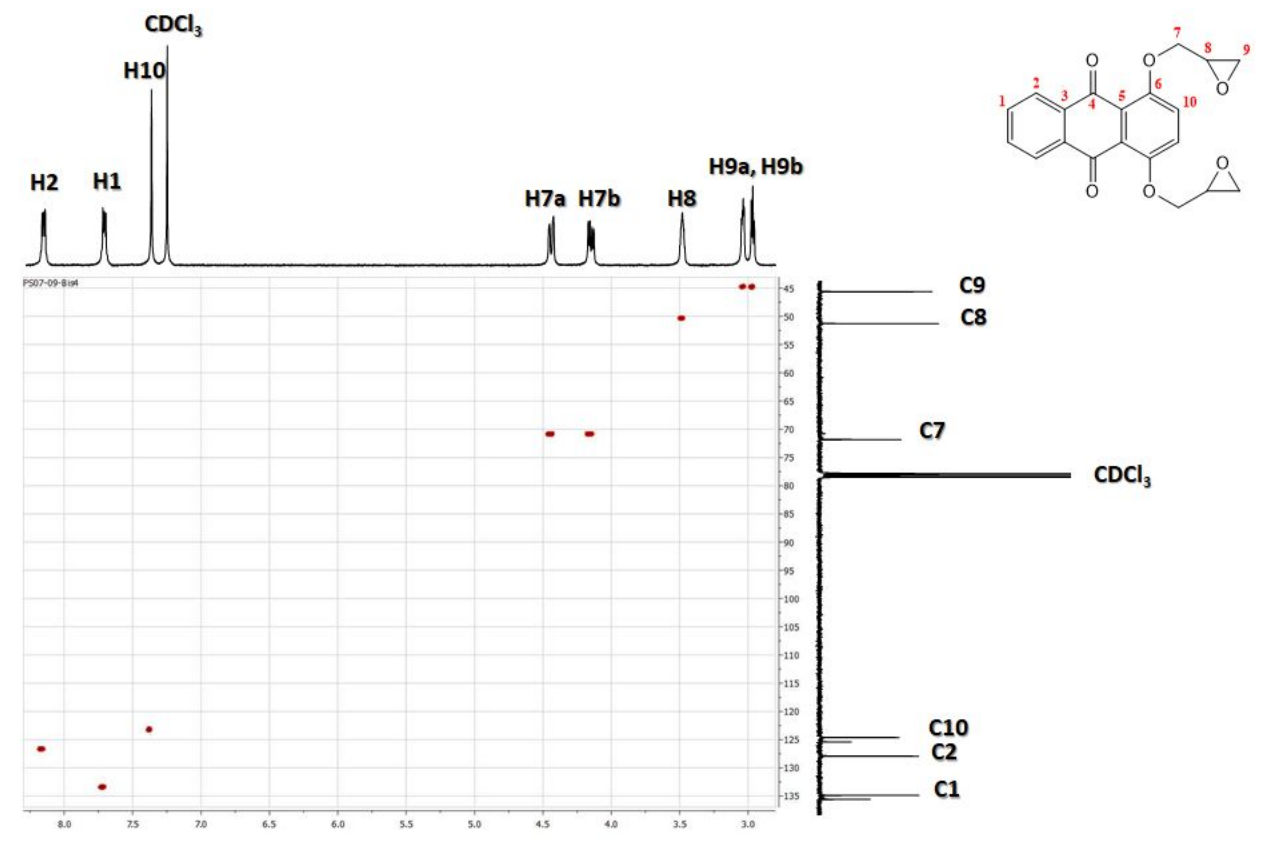

Figure S3. HSQC NMR spectra of A) $\mathbf{Q A}$ and B) $\mathbf{Q E}$ in $\mathrm{CDCl}_{3}$. 


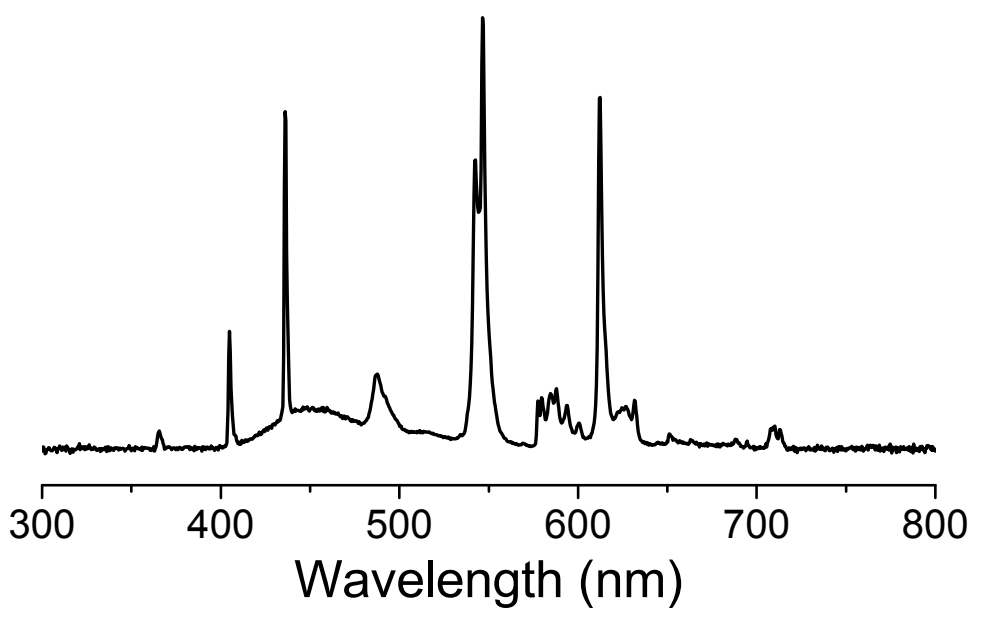

Figure S4. Emission spectrum of the lamps used during the antibacterial tests. Light intensity $=170 \mu \mathrm{mol} / \mathrm{m}^{2} / \mathrm{s}$ 
A

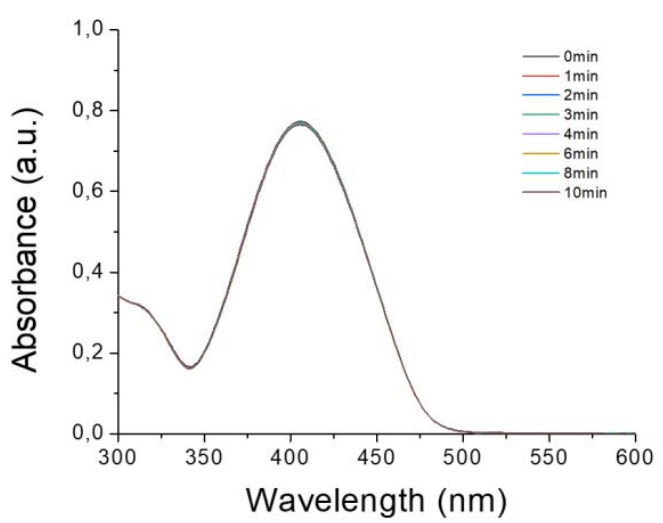

C

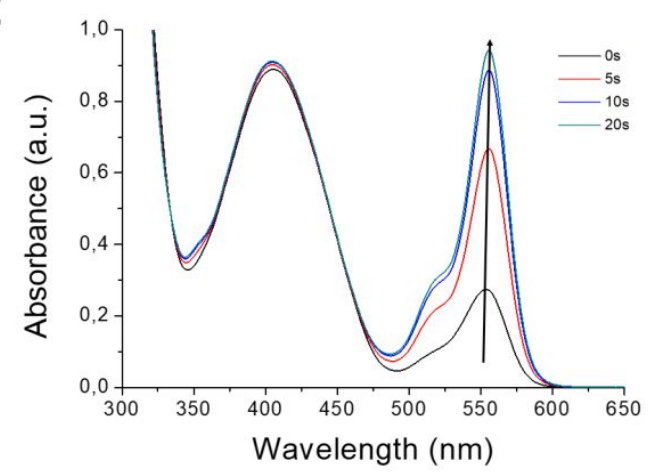

E

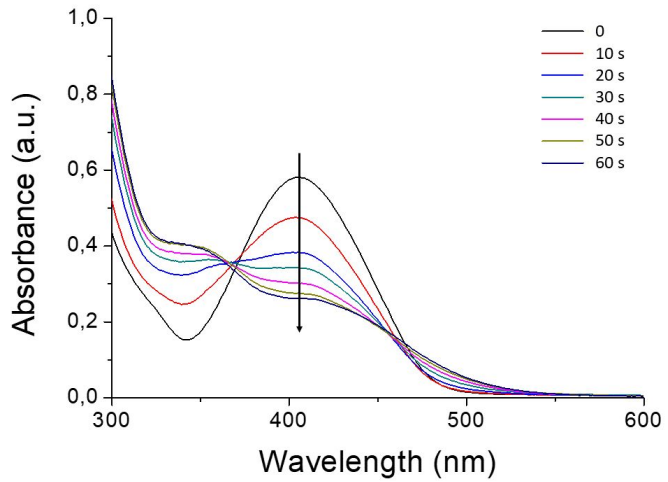

B

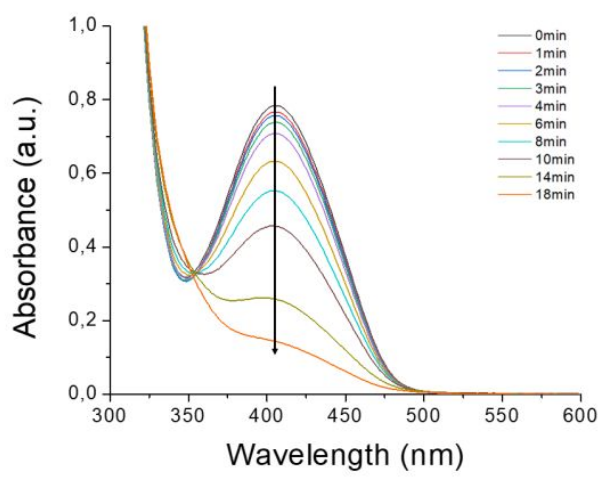

D

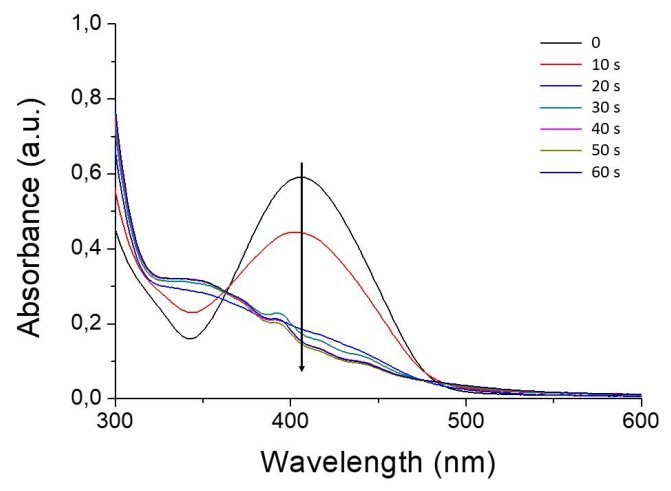

Figure S5. Steady state photolysis of A) $\mathbf{Q E}$, B) $\mathbf{Q E} / \operatorname{Iod}, \mathbf{C )} \mathbf{Q E} / \mathrm{Iod} /$ Rhodamine $\mathrm{B}$ in acetonitrile, D) QE/MDEA and E) QE/Trithiol after irradiation by LED@405 nm (60 $\left.\mathrm{mW} / \mathrm{cm}^{2}\right)$ under air conditions. $[\mathrm{QE}]=0.14 \mathrm{mM}$; [Iod] $=13 \mathrm{mM} ;[\mathrm{RhB}]=10^{-6} \mathrm{M}$; [MDEA $]=$ $30 \mathrm{mM}$ and $[$ Trithiol $]=10 \mathrm{mM}$. 


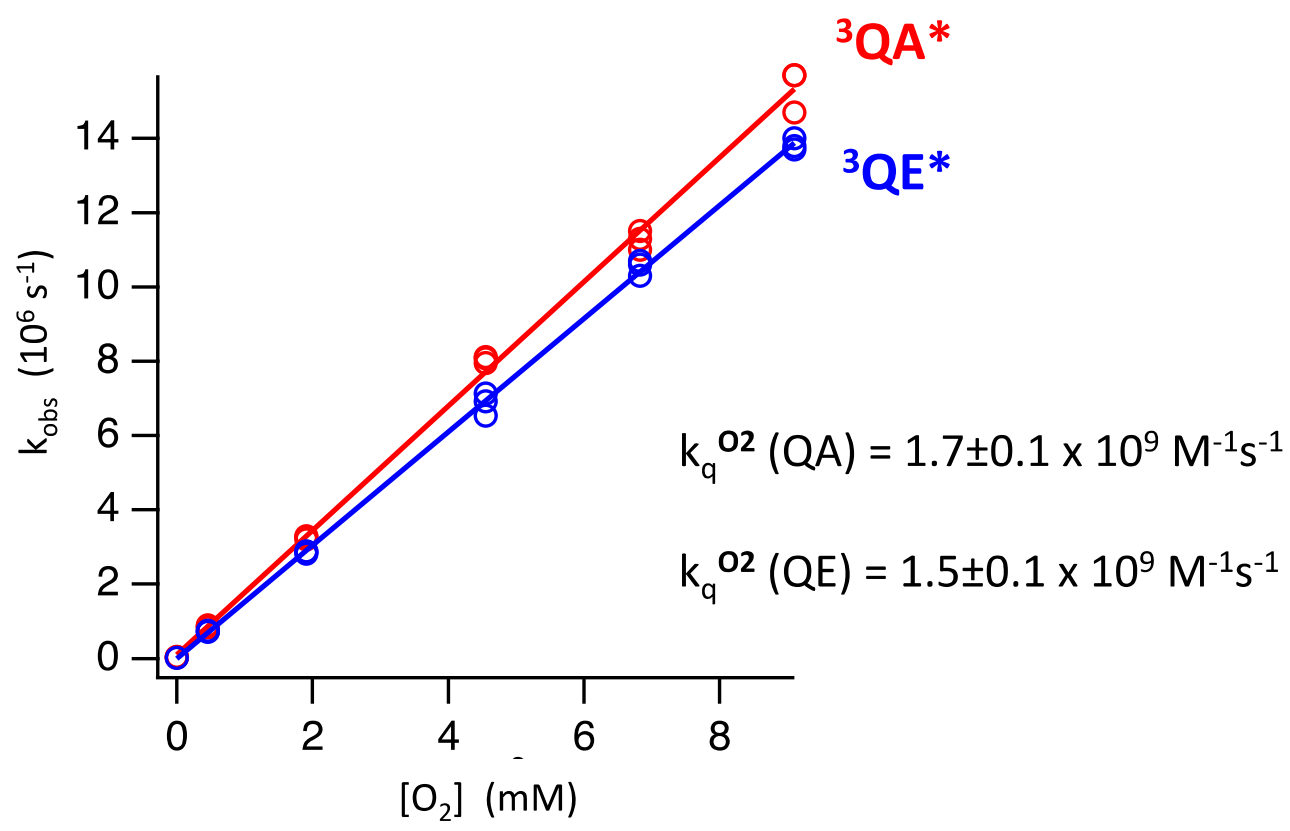

Figure S6. Determination of the bimolecular quenching rate constants $\mathrm{k}_{\mathrm{q}}$ of quenching of QA and QE triplet states by molecular oxygen using laser flash photolysis $\left(\lambda_{\mathrm{ex}}=355 \mathrm{~nm}, 7 \mathrm{~ns}\right.$ pulse width). Pseudo-first-order decay rate constant of QA and QE triplet state absorbance monitored at $580 \mathrm{~nm}$ vs. varying concentration of dissolved molecular oxygen in acetonitrile.

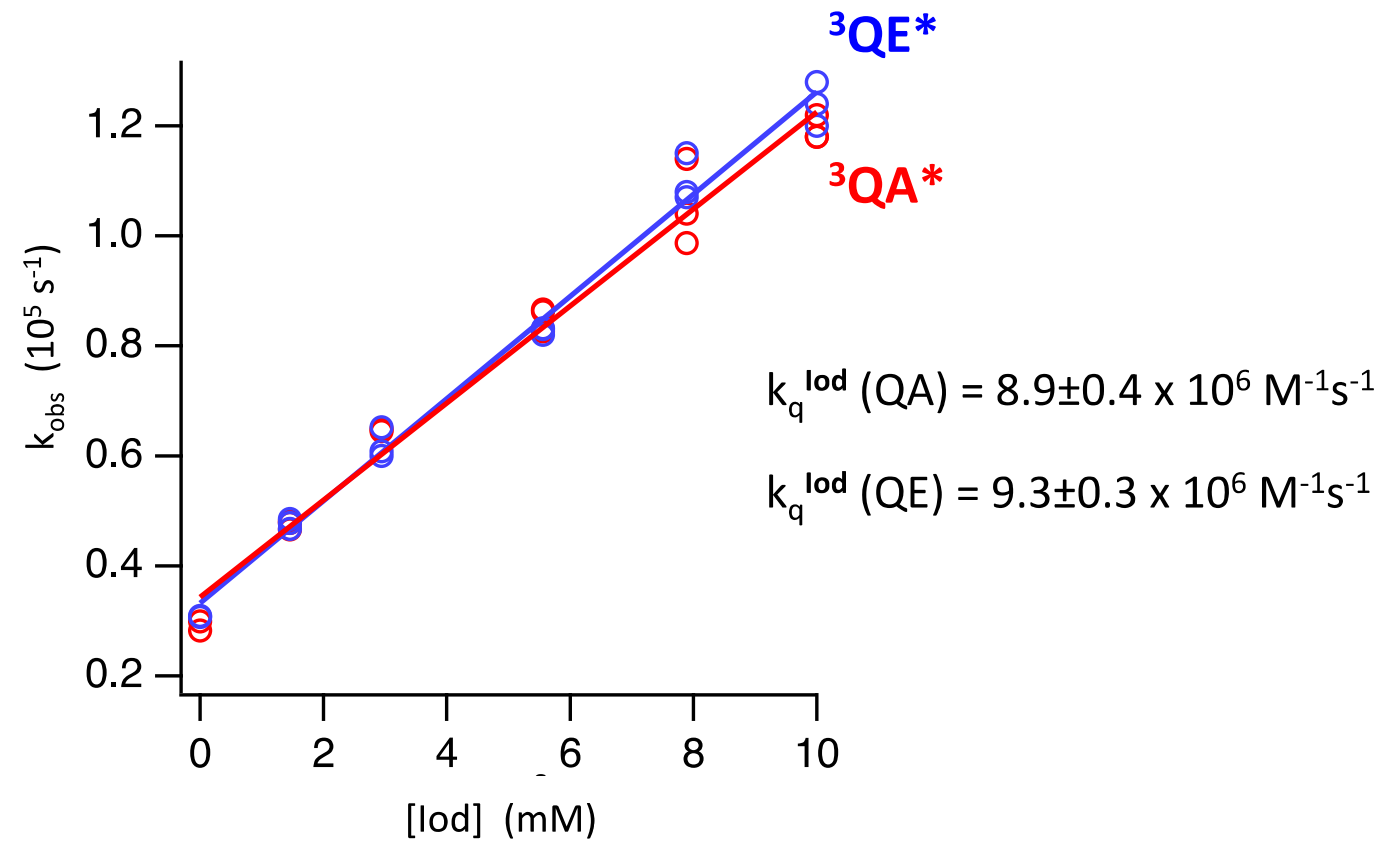

Figure S7. Determination of the bimolecular quenching rate constants $\mathrm{k}_{\mathrm{q}}^{\text {Iod }}$ of quenching of QA and QE triplet states by Iod using laser flash photolysis ( $\lambda_{\text {ex }}=355 \mathrm{~nm}, 7 \mathrm{~ns}$ pulse width). Pseudo-first-order decay rate constant of QA and QE triplet state absorption monitored at 580 $\mathrm{nm}$ vs. varying concentration of Iod in acetonitrile. 


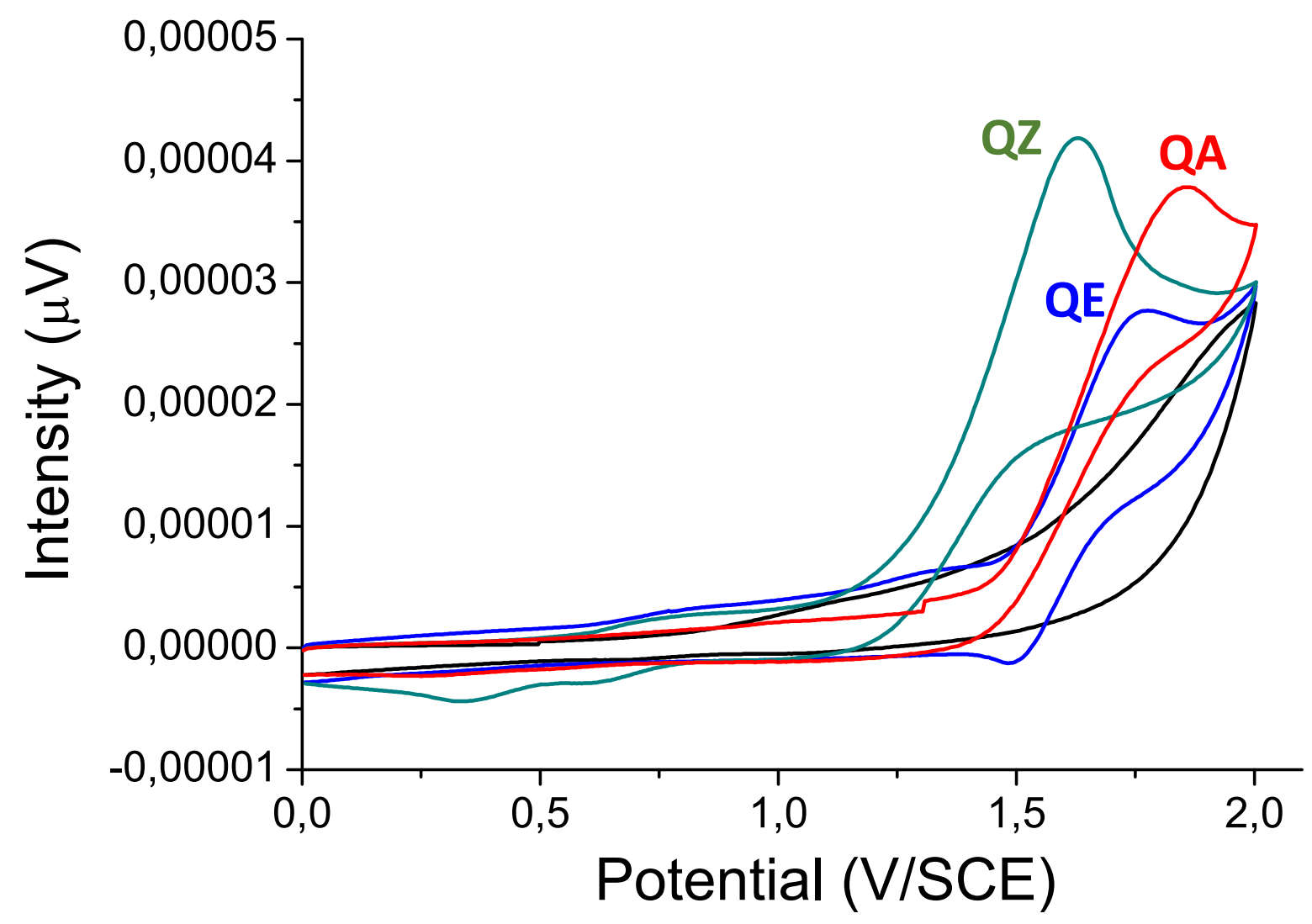

Figure S8. Cyclic voltammogram of quinizarin (QZ), allyl quinizarin (QA) and epoxidized quinizarin $(\mathbf{Q E})$ in acetonitrile $+10^{-3} \mathrm{M} n \mathrm{Bu}_{4} \mathrm{NBF}_{4}$ measured at a scan rate of $100 \mathrm{mV} / \mathrm{s}$. [QZ] $=[\mathbf{Q A}]=[\mathbf{Q E}]=10^{-3} \mathrm{M}$. 


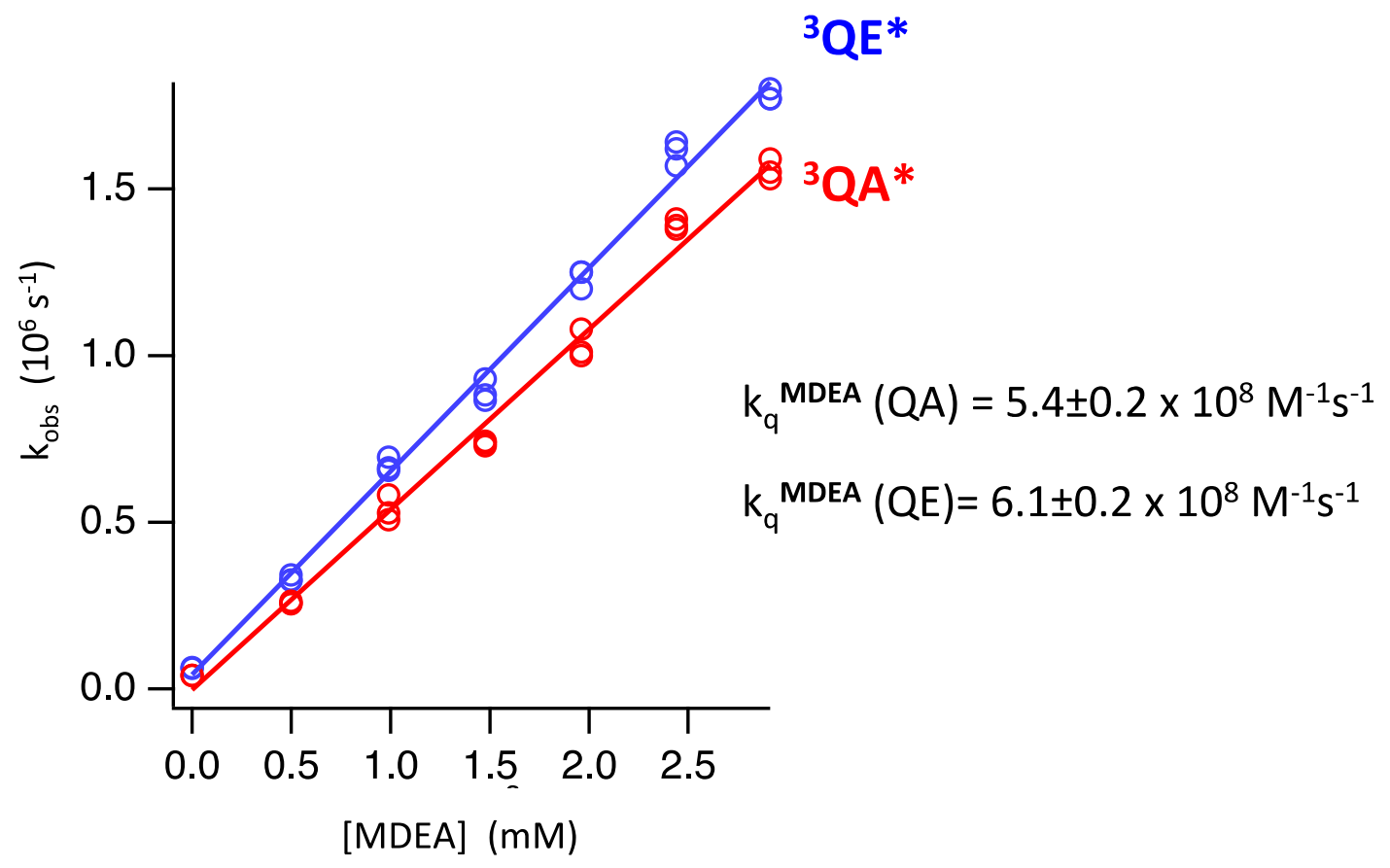

Figure S9. Determination of the bimolecular quenching rate constants $\mathrm{k}_{\mathrm{q}}$ of quenching of QA and QE triplet states by MDEA using laser flash photolysis ( $\lambda_{\mathrm{ex}}=355 \mathrm{~nm}, 7 \mathrm{~ns}$ pulse width). Pseudo-first-order decay rate constant of QA and QE triplet state absorption monitored at 490 $\mathrm{nm}$ vs. varying concentration of MDEA in acetonitrile.

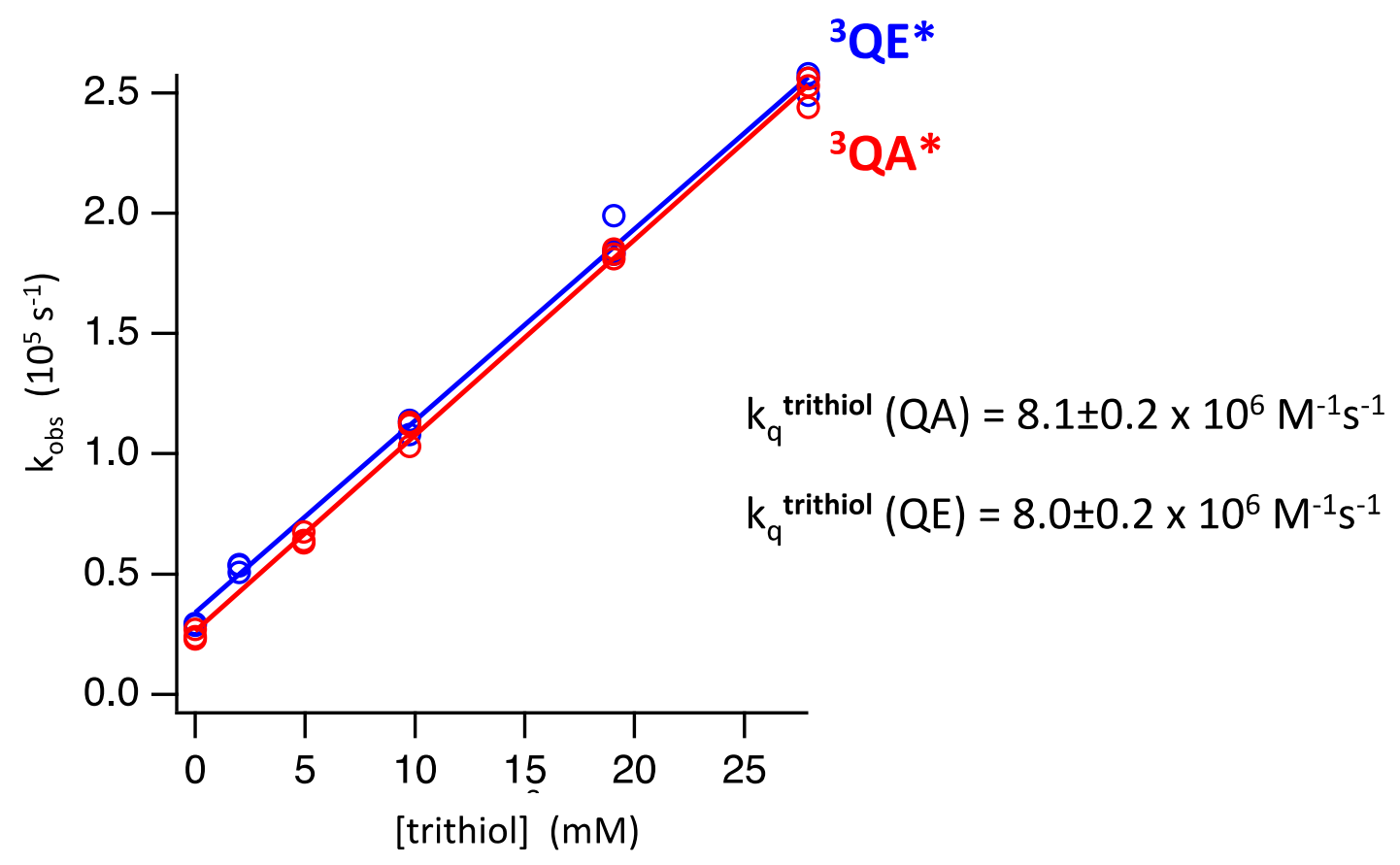

Figure S10. Determination of the bimolecular quenching rate constants $k_{q}$ of quenching of QA and QE triplet states by trithiol using laser flash photolysis $\left(\lambda_{\mathrm{ex}}=355 \mathrm{~nm}, 7 \mathrm{~ns}\right.$ pulse 
width). Pseudo-first-order decay rate constant of $\mathbf{Q A}$ and $\mathbf{Q E}$ triplet state absorption monitored at $580 \mathrm{~nm}$ vs. varying concentration of trithiol in acetonitrile.

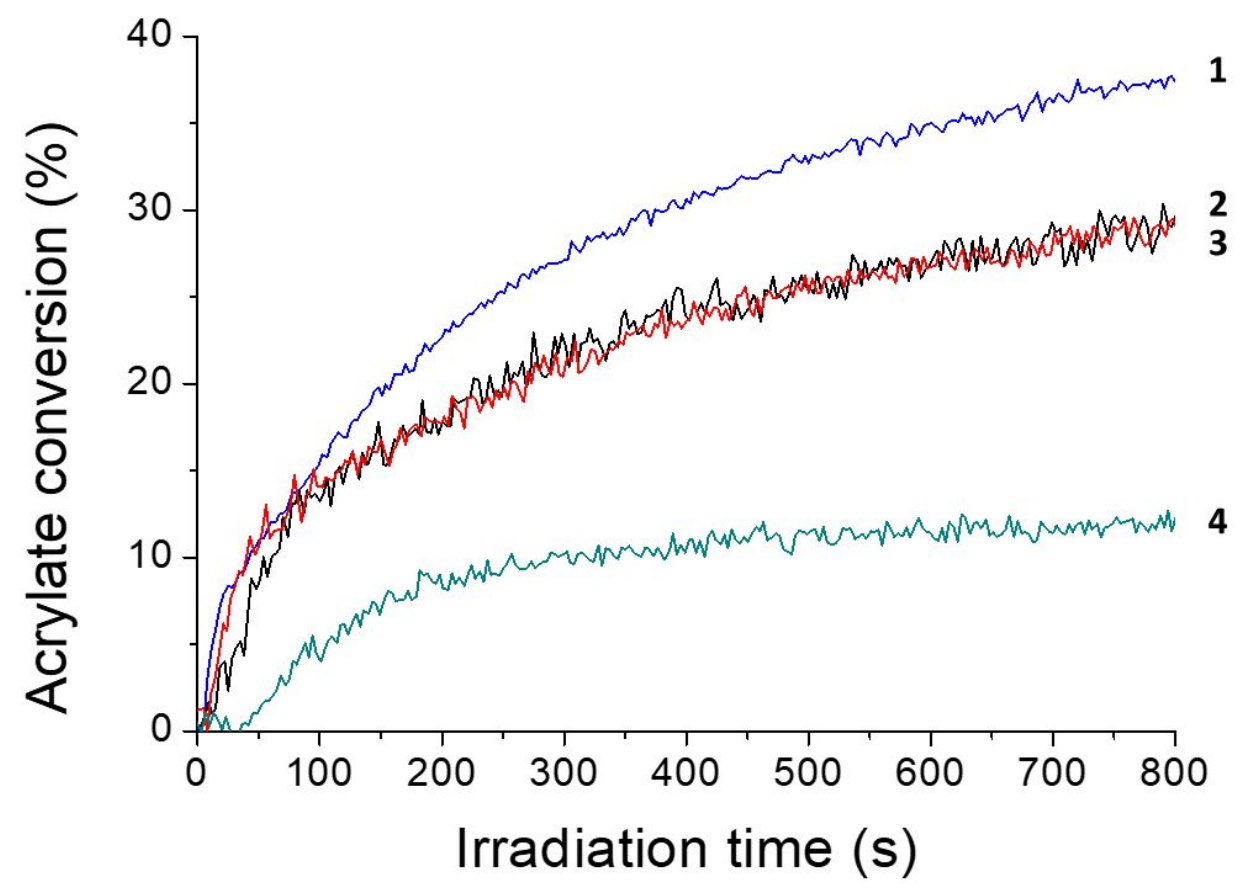

Figure S11. Photopolymerization profiles of TMPTA (acrylate function) in the presence of QZ/MDEA (0.5\%/2\%,w/w) in laminate upon (1) LED@405 nm, (2) LED@455 nm, (3) Xe lamp and (4)LED@470 nm. Thickness of the film =25 $\mu \mathrm{m}$.

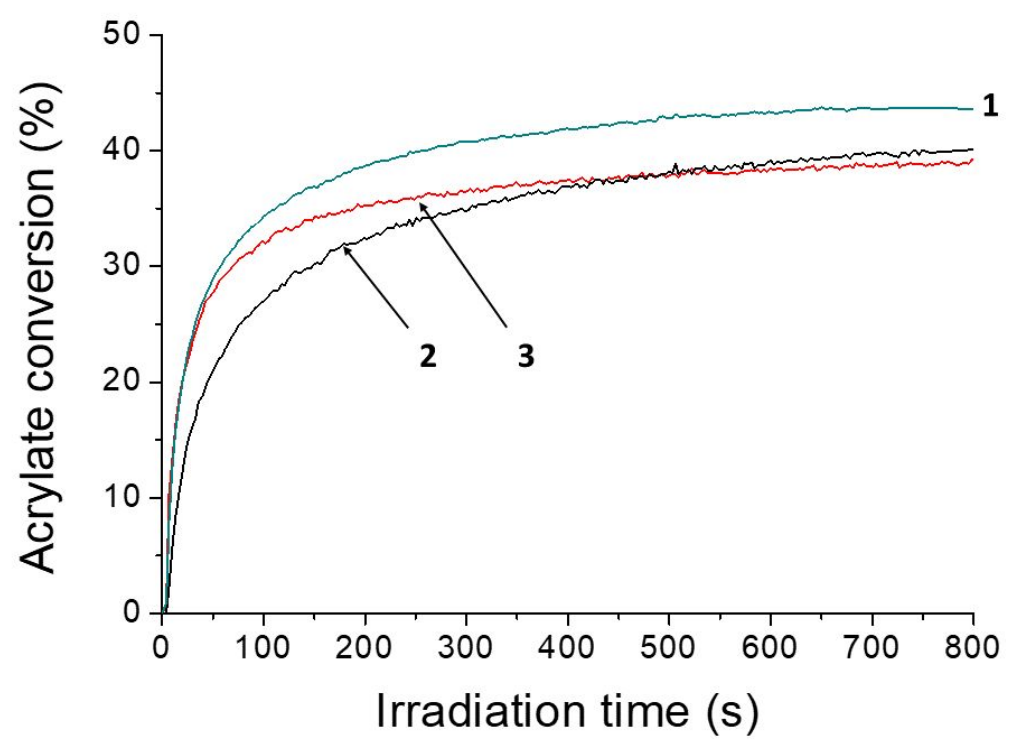

Figure S12. Photopolymerization profiles of TMPTA (acrylate function) in the presence of CQ/MDEA $(0.5 \% / 2 \%, w / w)$ in laminate upon (1) LED@470 nm, (2) Xe lamp and (3) LED@455 nm. No polymerization occurs under air. Thickness of the film =25 $\mu \mathrm{m}$. 

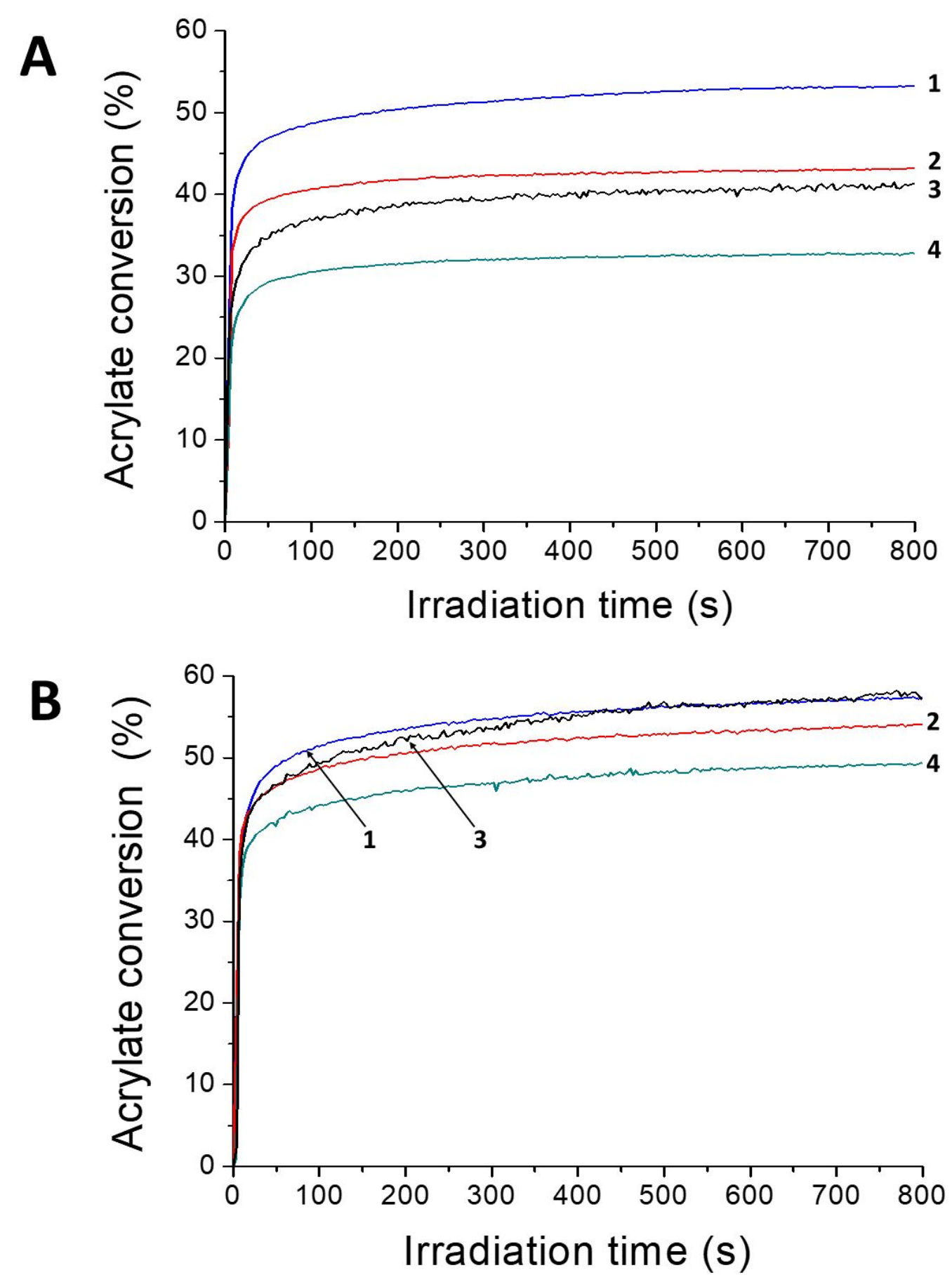

Figure S13. Photopolymerization profiles of TMPTA (acrylate function) in the presence of QE/MDEA (0.5\%/2\%, w/w) A) under air and B) in laminate upon (1) LED@405 nm, (2) LED@455 nm, (3) Xe lamp and (4)LED@470 nm. Thickness of the film =25 $\mu \mathrm{m}$. 


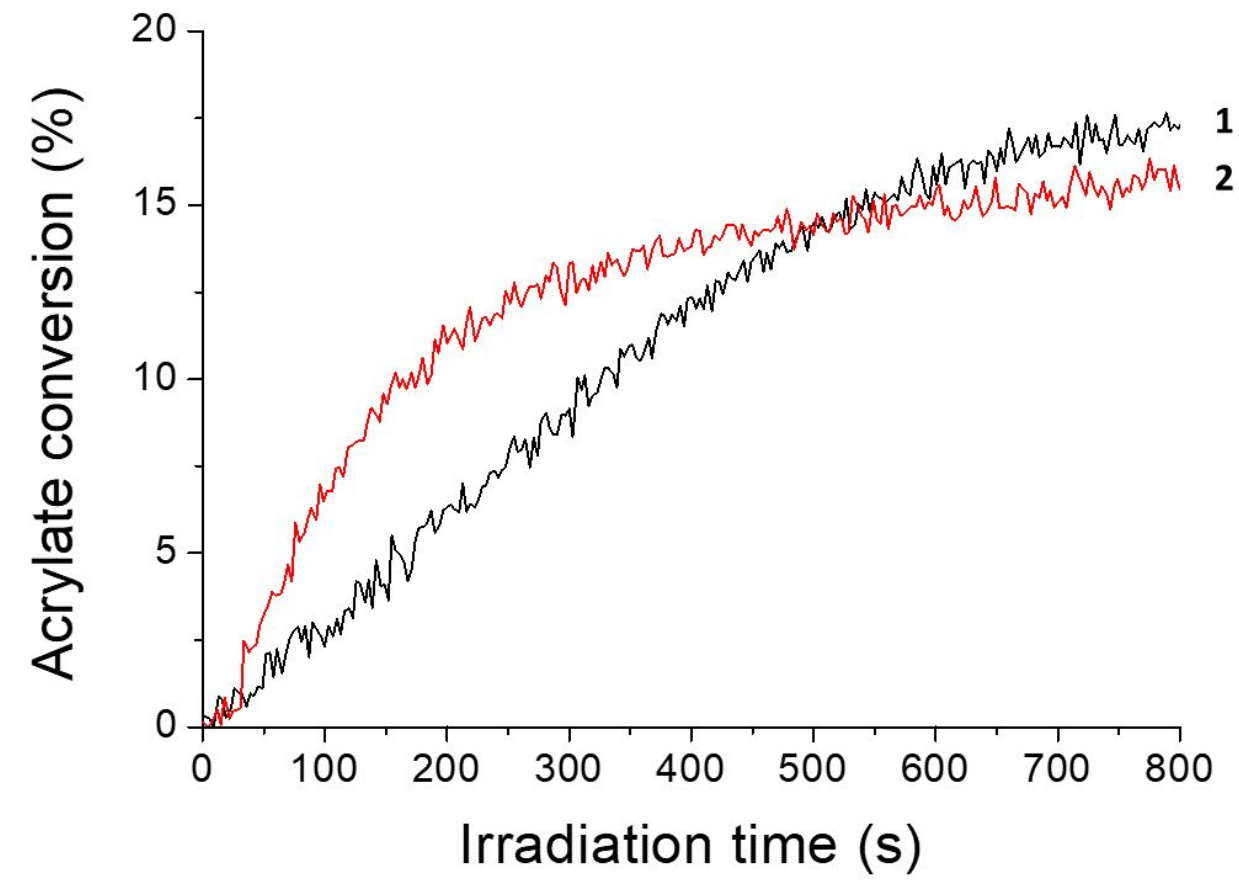

Figure S14. Photopolymerization profiles of TMPTA (acrylate function) in the presence of QZ/Iod (0.5\%/2\%, w/w) upon LED@405 nm (1) under air and (2) in laminate. Thickness of the film $=25 \mu \mathrm{m}$.

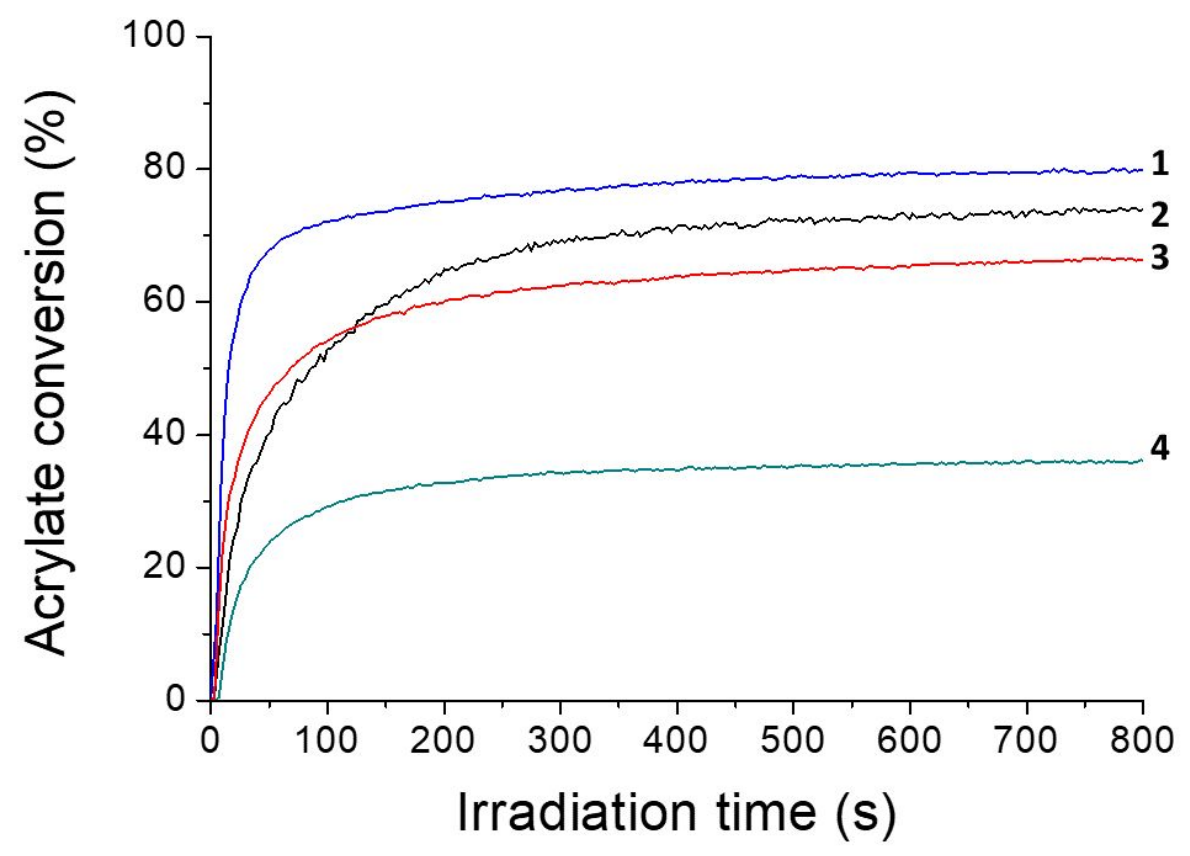

Figure S15. Photopolymerization profiles of TMPTA (acrylate function) in the presence of QE/Iod (0.5\%/2\%,w/w) in laminate upon (1)LED@405 nm, (2) Xe lamp, (3) LED@455 nm and (4) LED@470 nm. Thickness of the film=25 $\mu \mathrm{m}$. 


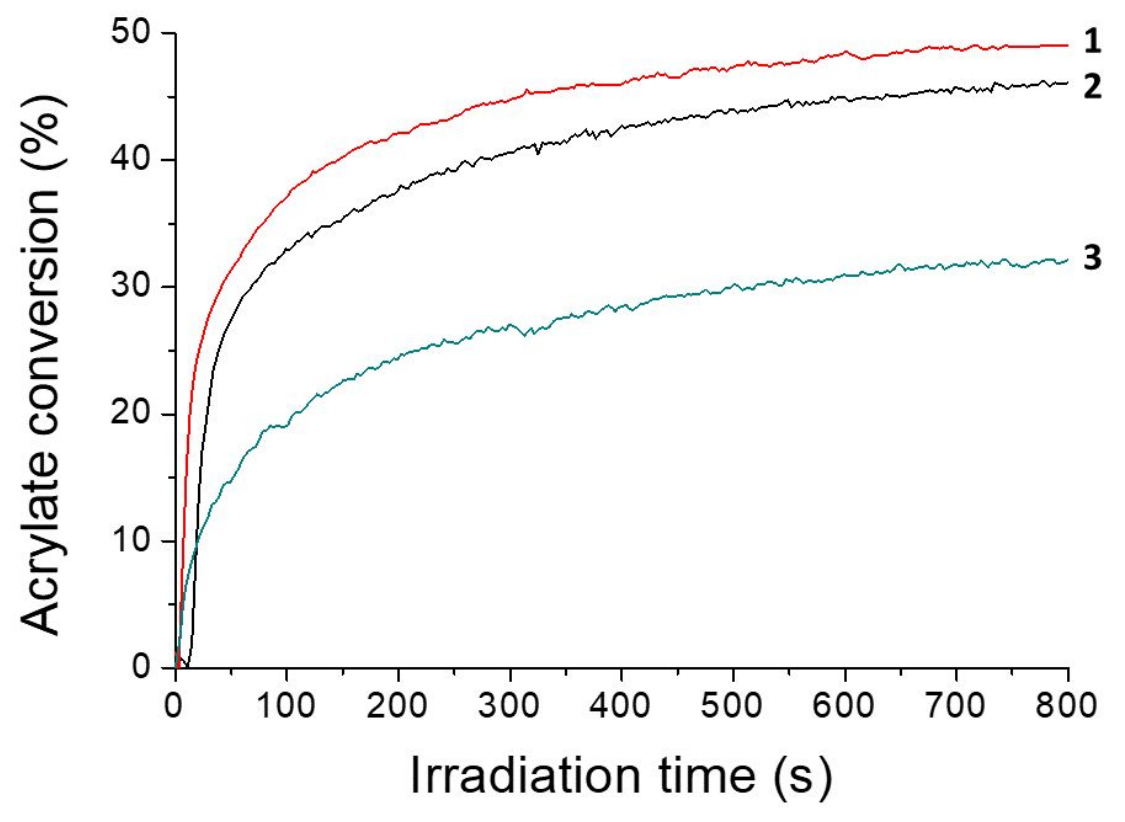

Figure S16. Photopolymerization profiles of TMPTA (acrylate function) in the presence of CQ/Iod (0.5\%/2\%,w/w) in laminate under (1) LED@455 nm (2) Xe lamp and (3) LED@470 $\mathrm{nm}$ exposure. Thickness of the film $=25 \mu \mathrm{m}$. 

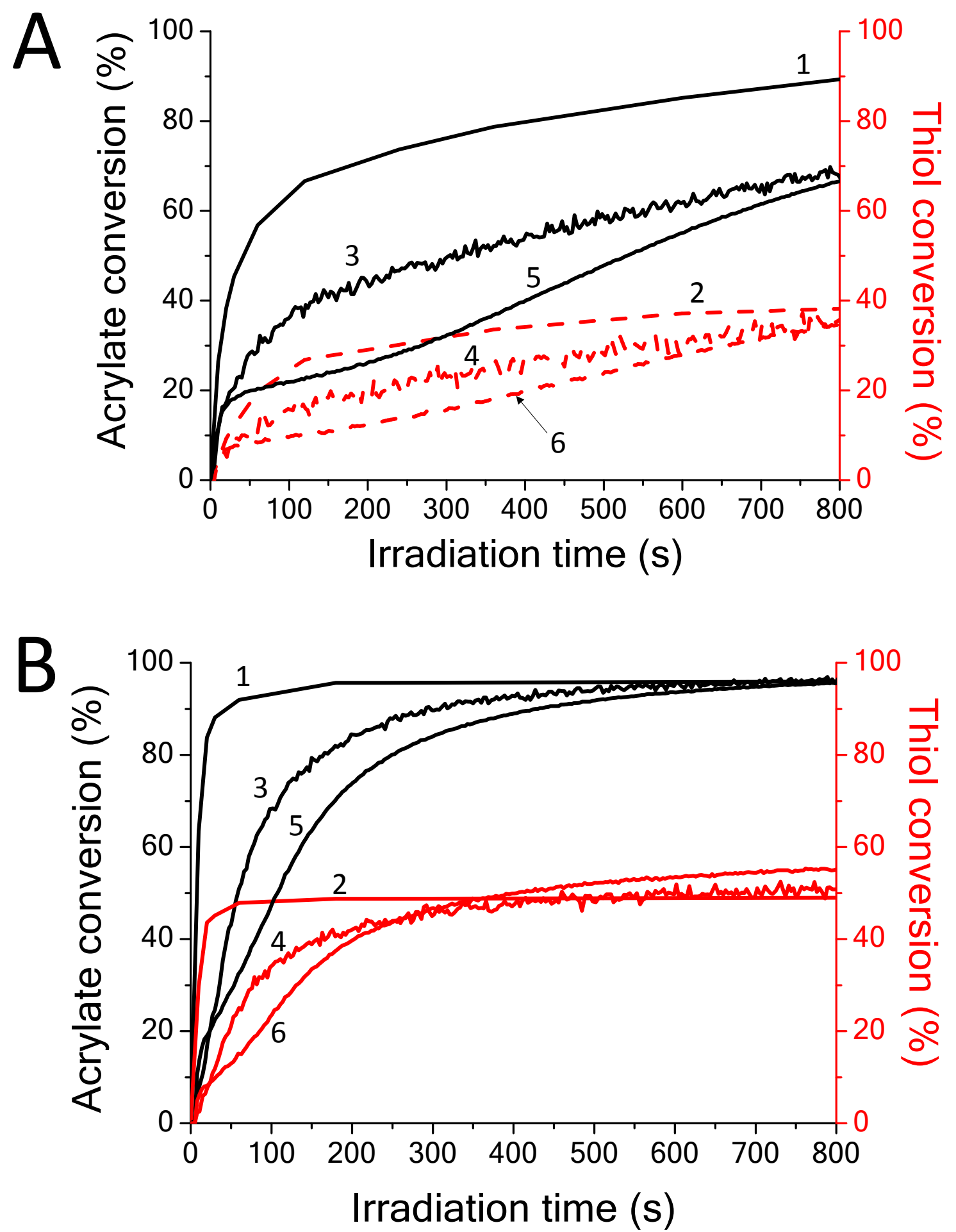

Figure S17. Photopolymerization profiles of a TMPTA/Trithiol blend $(43 \% / 57 \%, w / w)$ in the presence of A) QA (0.5\%) and B) QA/Iod (0.5\%/2\%, w/w) under air upon LED@405 nm (curves 1 and 2), Xe lamp (curves 3 and 4) and LED@455 nm (curves 5 and 6). Curves 1, 3 and $5=$ acrylate conversions; Curves 2,4 and $6=$ thiol conversions. Thickness of the film $=$ $25 \mu \mathrm{m}$. 

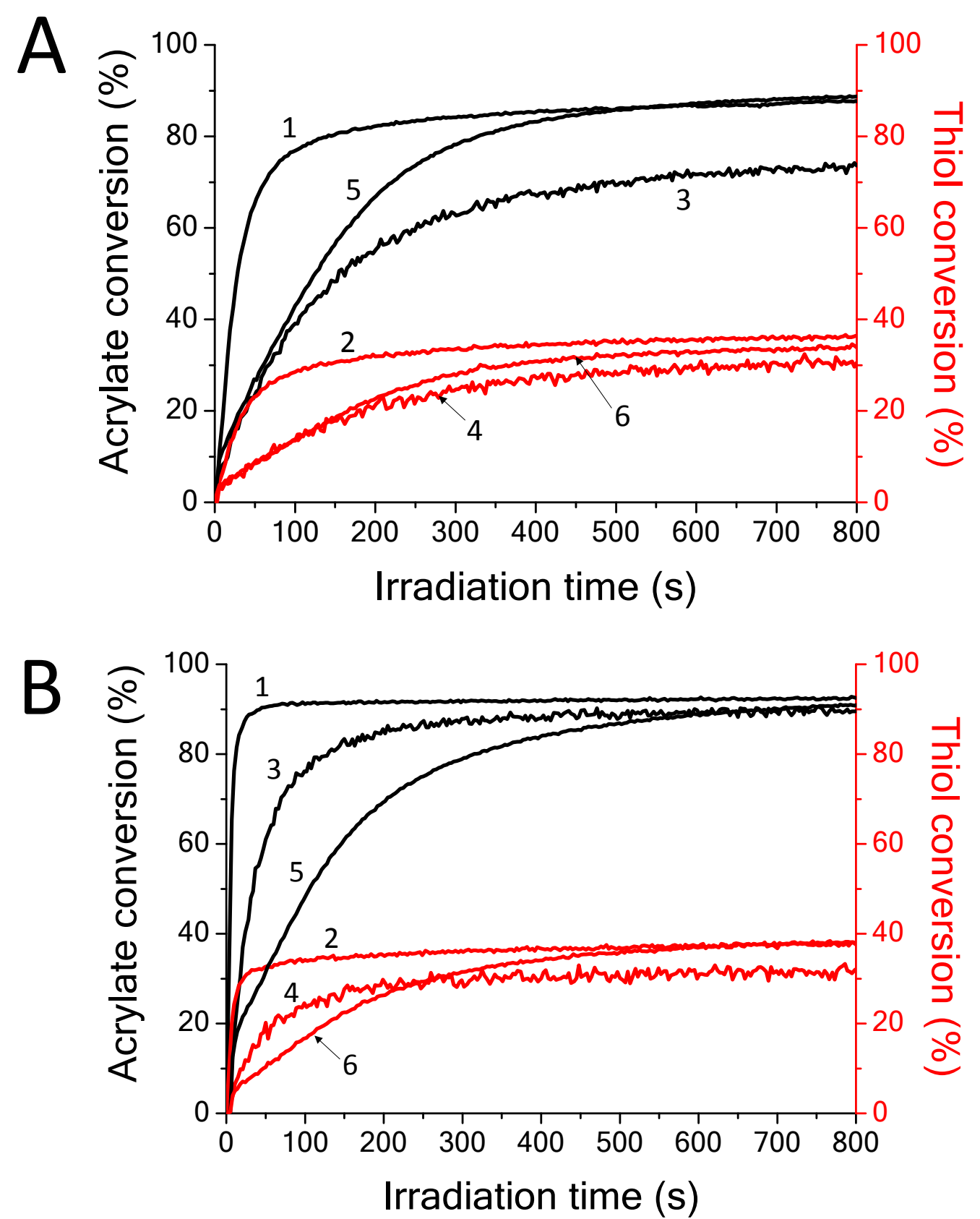

Figure S18. Photopolymerization profiles of a TMPTA/Trithiol blend $(43 \% / 57 \%, \mathrm{w} / \mathrm{w})$ in the presence of A) QE $(0.5 \%)$ and B) QE/Iod $(0.5 \% / 2 \%, \mathrm{w} / \mathrm{w})$ in laminate upon LED@405 nm (curves 1 and 2), Xe lamp (curves 3 and 4) and LED@455 nm (curves 5 and 6). Curves 1, 3 and $5=$ acrylate conversions; Curves 2,4 and $6=$ thiol conversions. Thickness of the film $=$ $25 \mu \mathrm{m}$. 


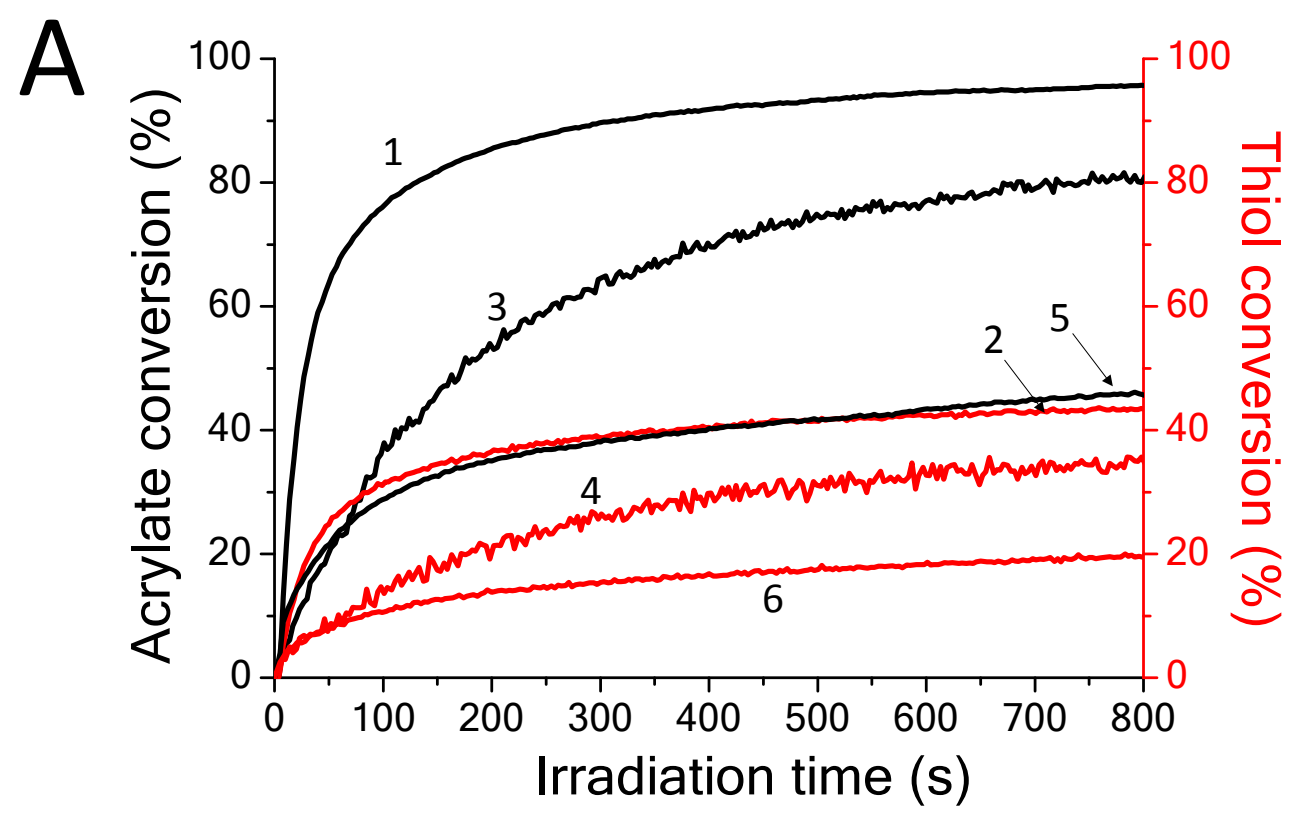

$\mathrm{B}$

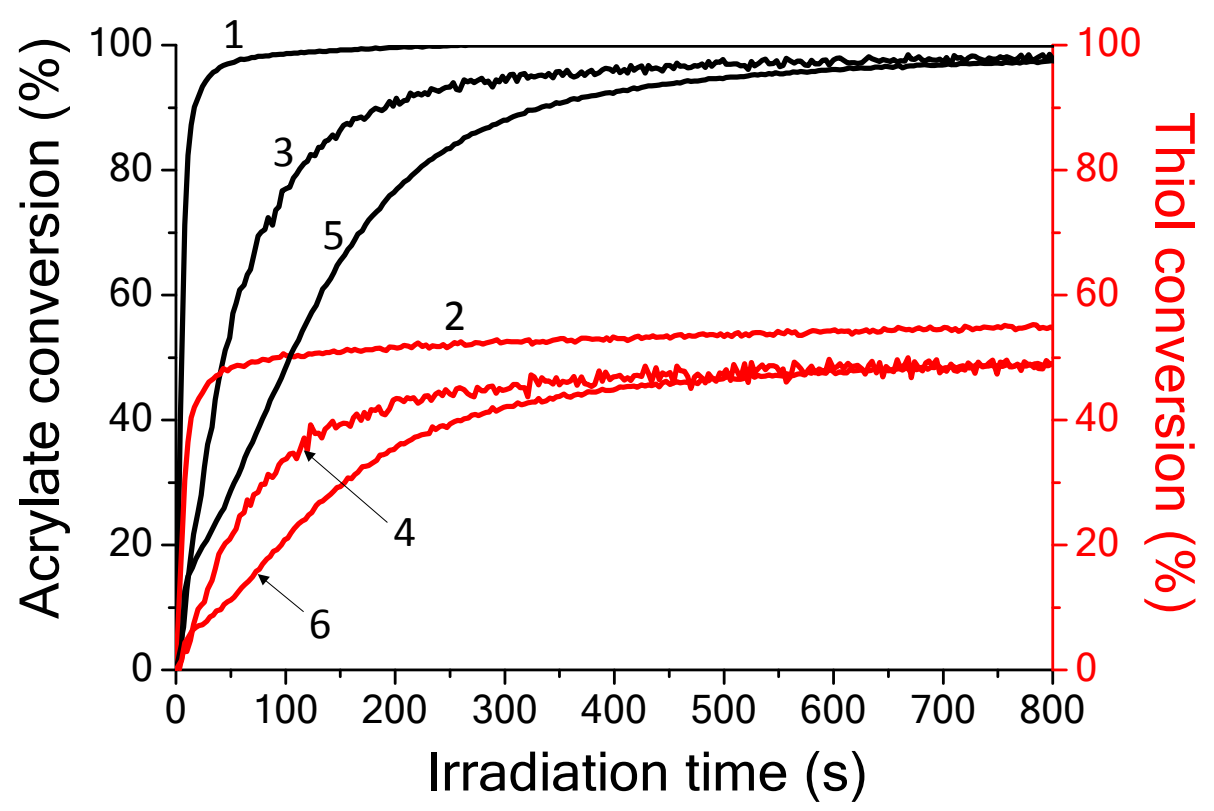

Figure S19. Photopolymerization profiles of a TMPTA/Trithiol blend $(43 \% / 57 \%$, w/w) in the presence of A) QE (0.5\%) and B) QE/Iod (0.5\%/2\%, w/w) under air upon LED@405 nm (curves 1 and 2), Xe lamp (curves 3 and 4) and LED@455 nm (curves 5 and 6). Curves 1, 3 and $5=$ acrylate conversions; Curves 2, 4 and $6=$ thiol conversions. Thickness of the film $=$ $25 \mu \mathrm{m}$. 

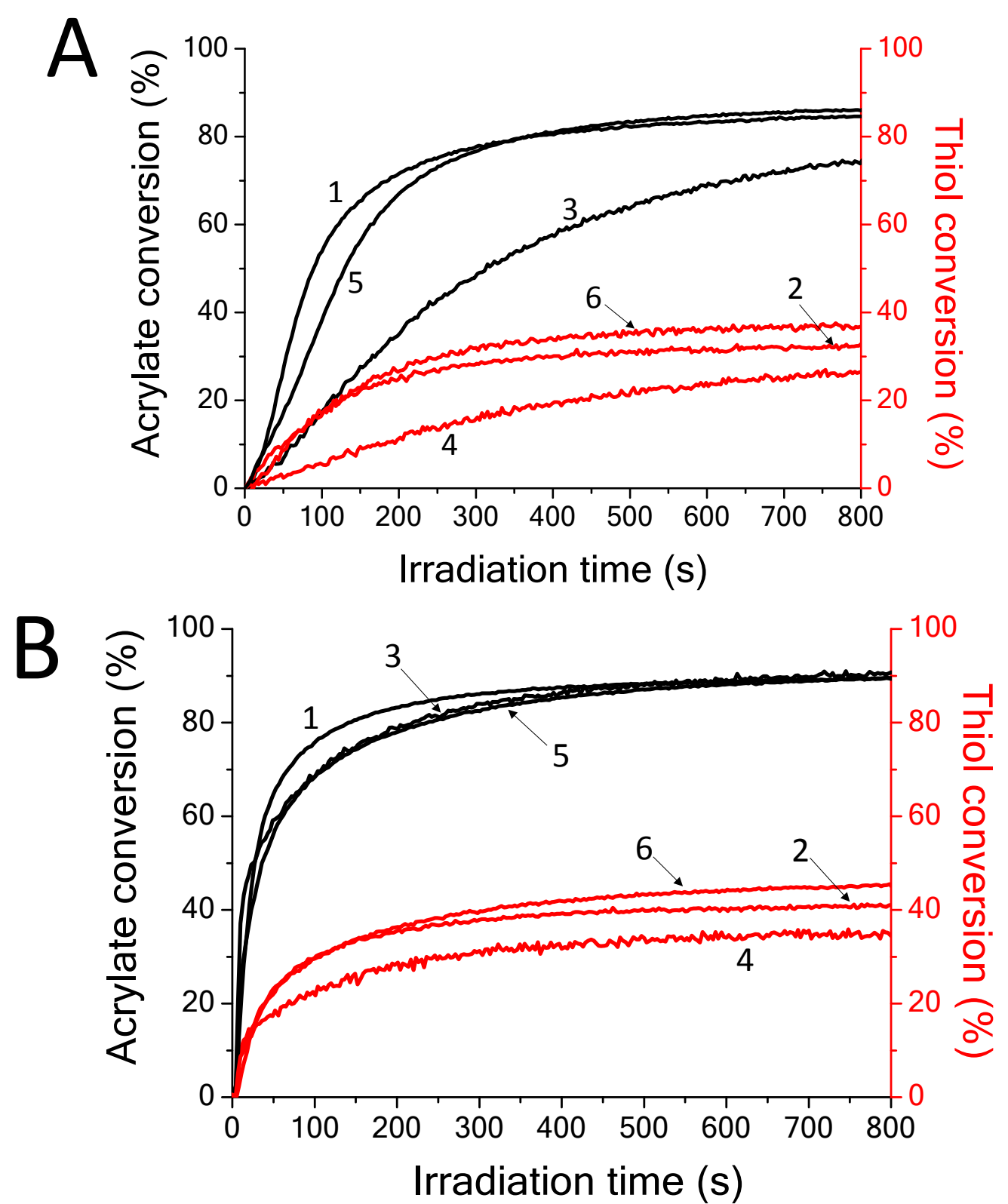

Figure S20. Photopolymerization profiles of a TMPTA/Trithiol blend (43\%/57\%, w/w) in the presence of A) QZ (0.5\%) and B) QZ/Iod $(0.5 \% / 2 \%, \mathrm{w} / \mathrm{w})$ in laminate upon LED@405 nm (curves 1 and 2), Xe lamp (curves 3 and 4) and LED@455 nm (curves 5 and 6). Curves 1, 3 and $5=$ acrylate conversions; Curves 2, 4 and $6=$ thiol conversions. Thickness of the film $=$ $25 \mu \mathrm{m}$. 

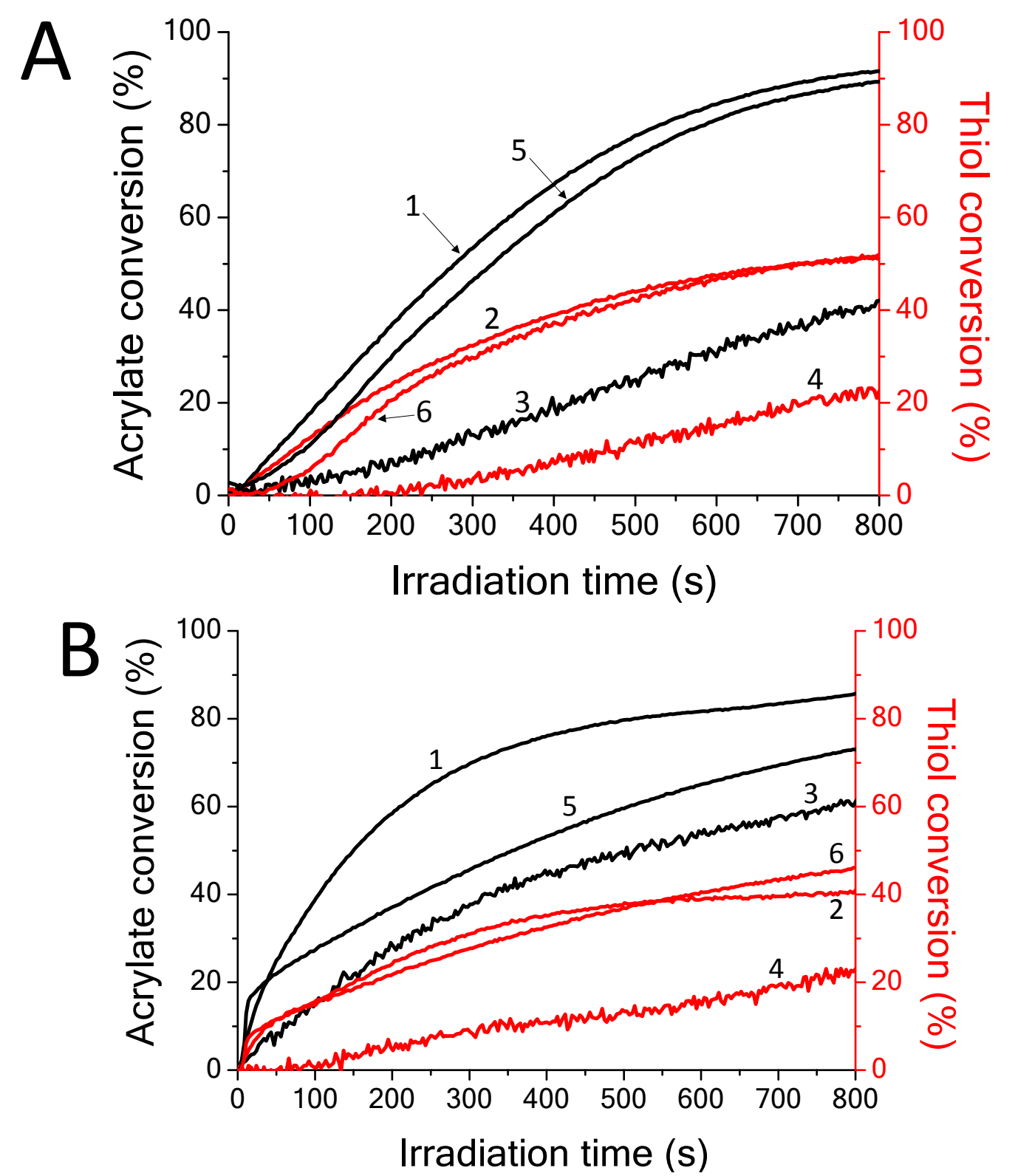

Figure S21. Photopolymerization profiles of a TMPTA/Trithiol blend $(43 \% / 57 \%, \mathrm{w} / \mathrm{w})$ in the presence of A) QZ (0.5\%) and B) QZ/Iod $(0.5 \% / 2 \%$, w/w) under air upon LED@405 nm (curves 1 and 2), Xe lamp (curves 3 and 4) and LED@455 nm (curves 5 and 6). Curves 1, 3 and $5=$ acrylate conversions; Curves 2, 4 and $6=$ thiol conversions. Thickness of the film $=$ $25 \mu \mathrm{m}$. 

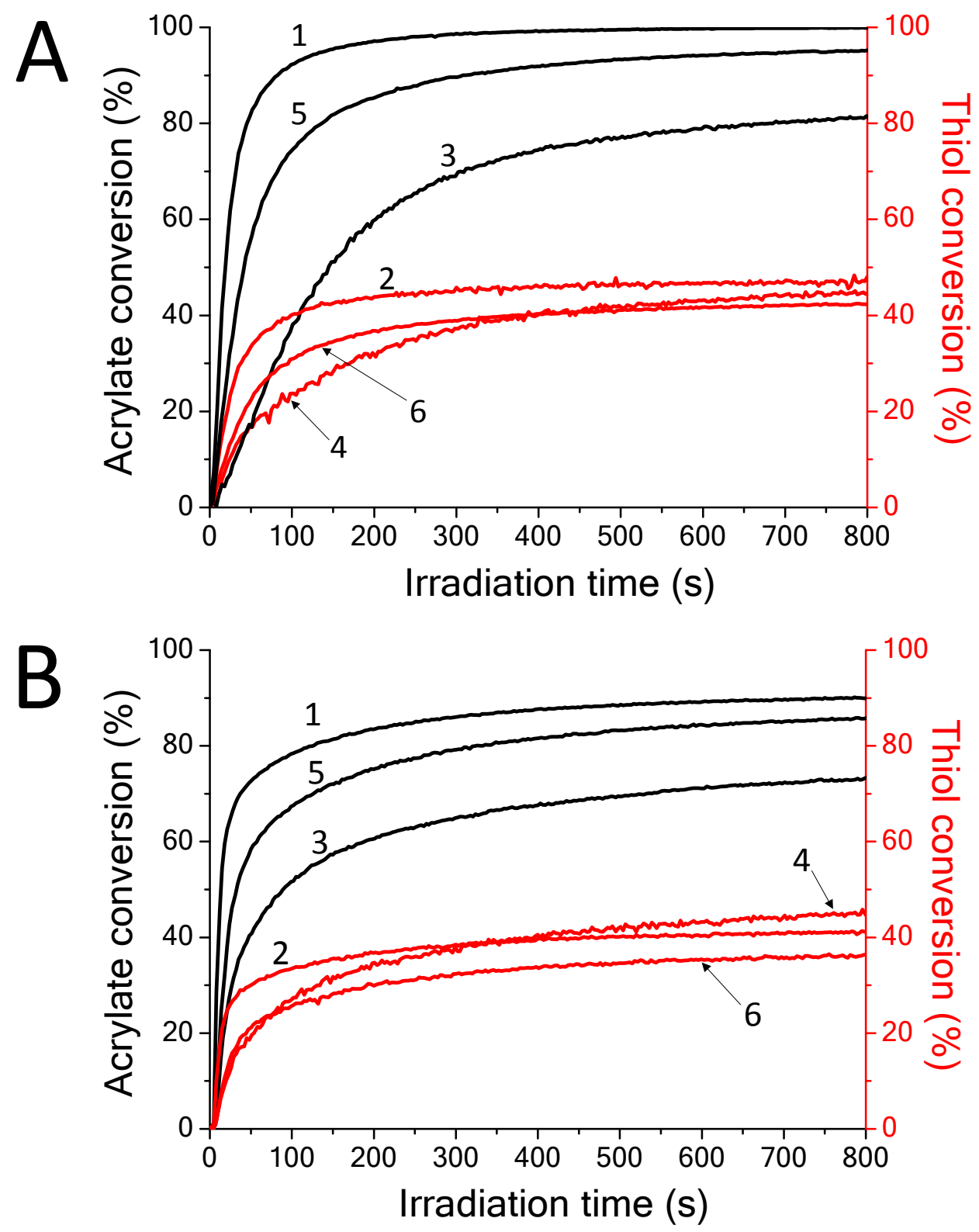

Figure S22. Photopolymerization profiles of a TMPTA/Trithiol blend $(43 \% / 57 \%, \mathrm{w} / \mathrm{w})$ in the presence of A) CQ $(0.5 \%)$ and B) CQ/Iod $(0.5 \% / 2 \%, w / w)$ in laminate upon LED@455 nm (curves 1 and 2), Xe lamp (curves 3 and 4) and LED@470 nm (curves 5 and 6). Curves 1, 3 and $5=$ acrylate conversions; Curves 2,4 and $6=$ thiol conversions. Thickness of the film $=$ $25 \mu \mathrm{m}$. 

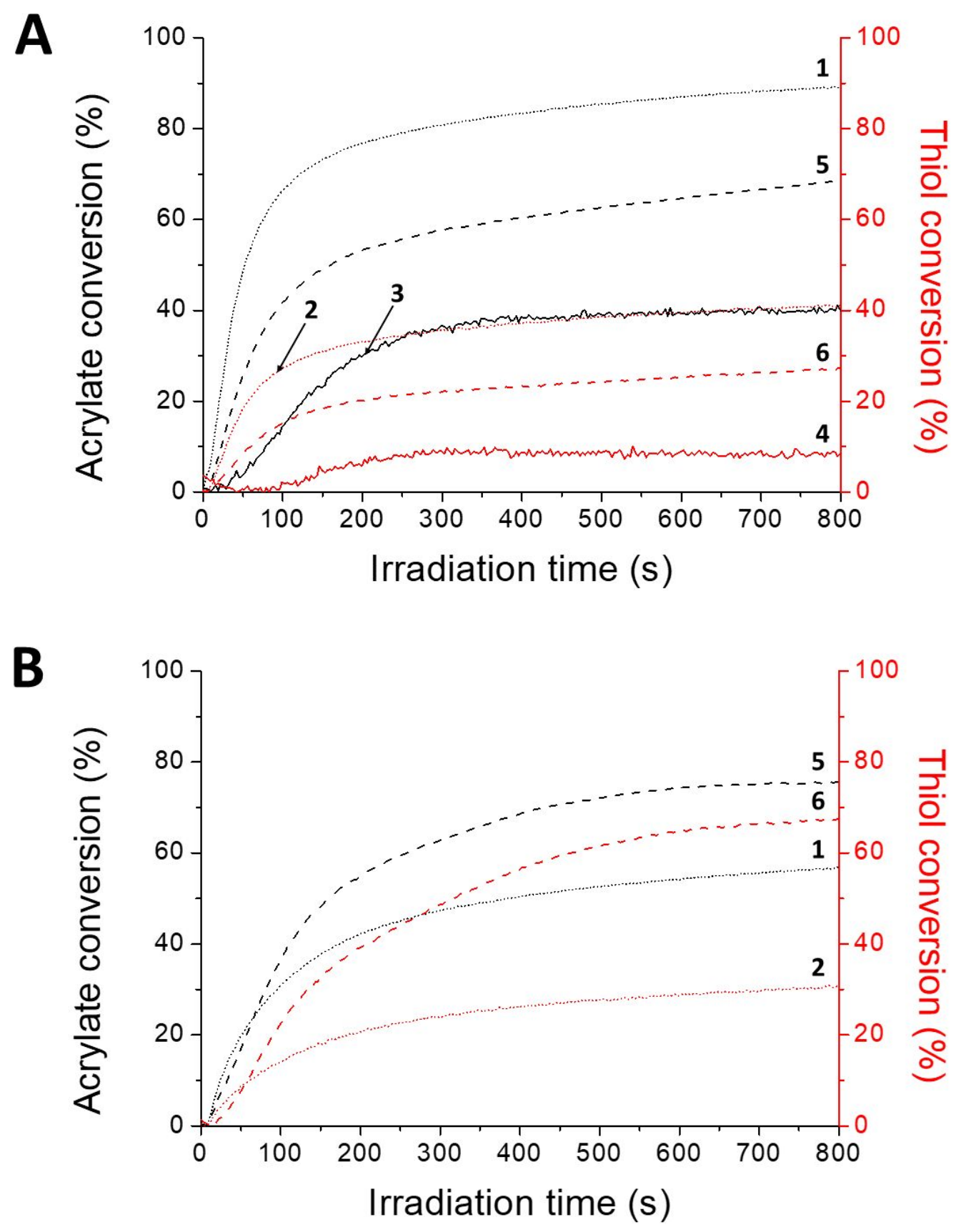

Figure S23. Photopolymerization profiles of a TMPTA/Trithiol blend $(43 \% / 57 \%, \mathrm{w} / \mathrm{w})$ in the presence of A) CQ $(0.5 \%)$ and B) CQ/Iod $(0.5 \% / 2 \%$, w/w) under air upon LED@455 nm (curves 1 and 2), Xe lamp (curves 3 and 4) and LED@470 nm (curves 5 and 6). Curves 1, 3 and $5=$ acrylate conversions; Curves 2,4 and $6=$ thiol conversions. Thickness of the film $=$ $25 \mu \mathrm{m}$. 

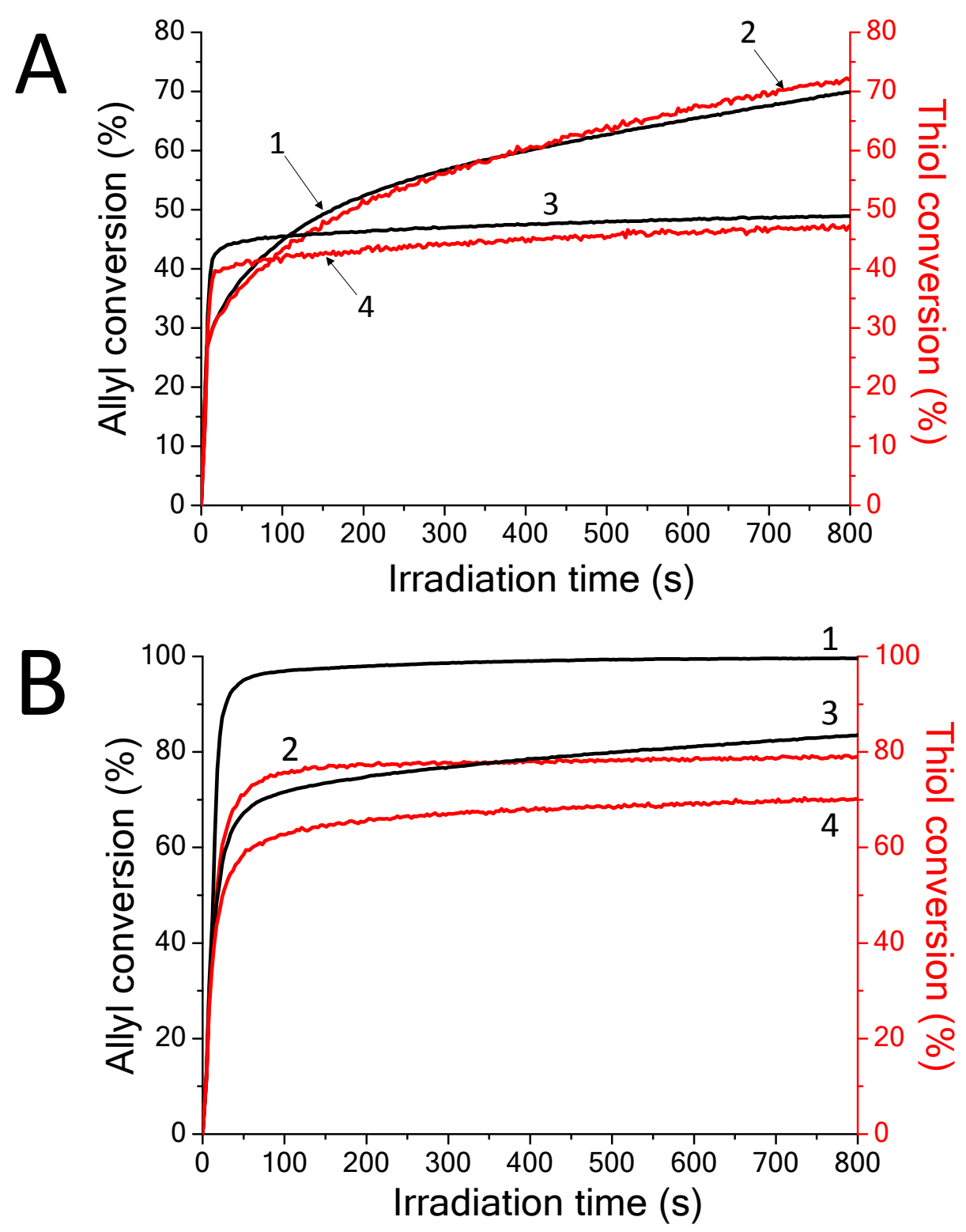

Figure S24. Kinetic profiles of the allyl and thiol functions in the DVE/trithiol formulation $(43 \% / 57 \%, \mathrm{w} / \mathrm{w})$ in the presence of A) QA $(0.5 \mathrm{wt} \%)$ and B) QA/Iod $(0.5 \% / 2 \%, \mathrm{w} / \mathrm{w})$ under air upon LED@455 nm (curves 1 and 2) and LED@470 nm (curves 3 and 4) exposure. Curves 1 and 3 = acrylate conversions; Curves 2 and $4=$ thiol conversions. Thickness of the film $=25 \mu \mathrm{m}$. 

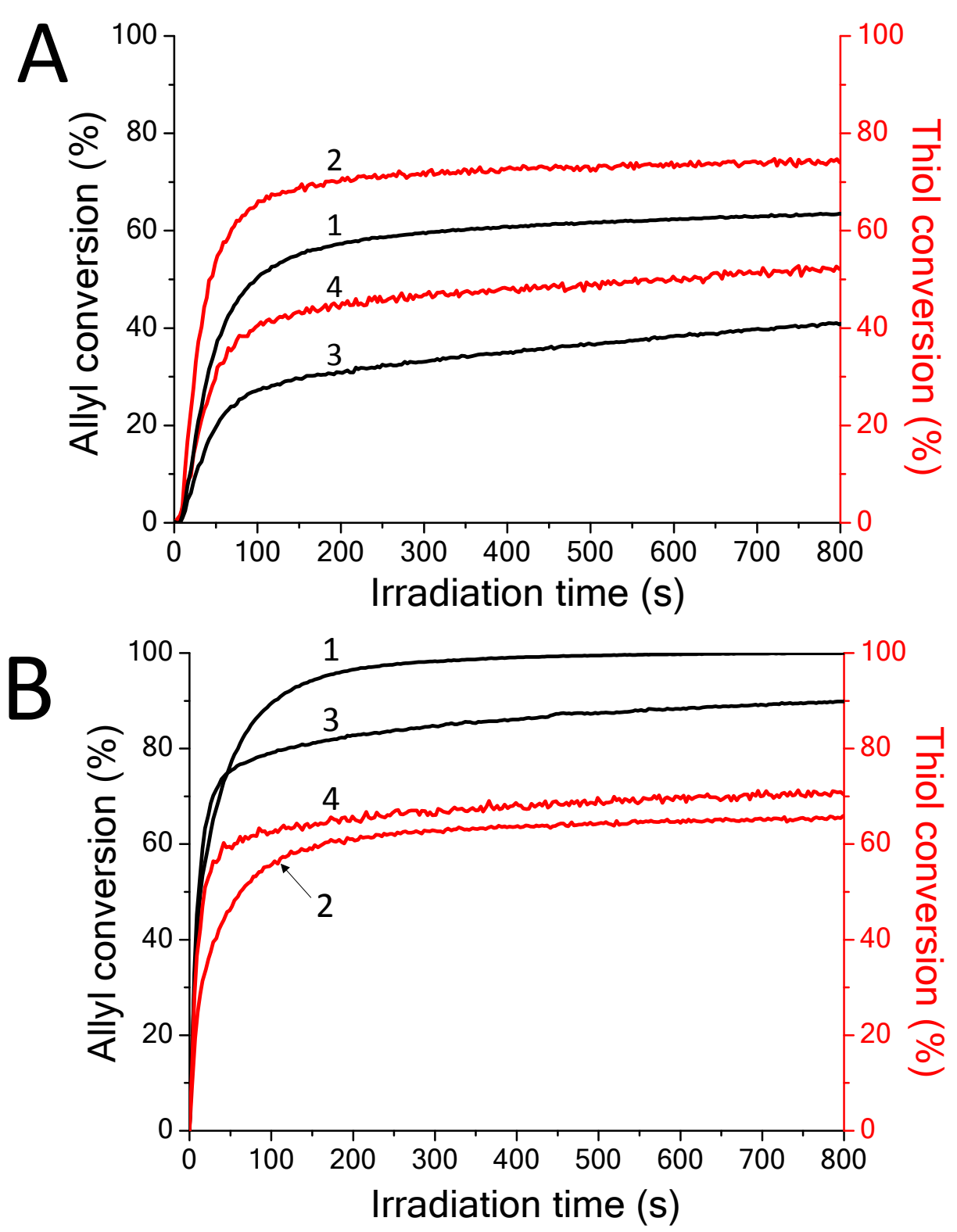

Figure S25. Kinetic profiles of the allyl and thiol functions in the DVE/trithiol formulation $(43 \% / 57 \%, \mathrm{w} / \mathrm{w})$ in the presence of A) CQ $(0.5 \mathrm{wt} \%)$ and B) CQ/Iod $(0.5 \% / 2 \%, \mathrm{w} / \mathrm{w})$ in laminate upon LED@455 nm (curves 1 and 2) and LED@470 nm (curves 3 and 4) exposure. Curves 1 and 3 = acrylate conversions; Curves 2 and $4=$ thiol conversions. Thickness of the film $=25 \mu \mathrm{m}$ 

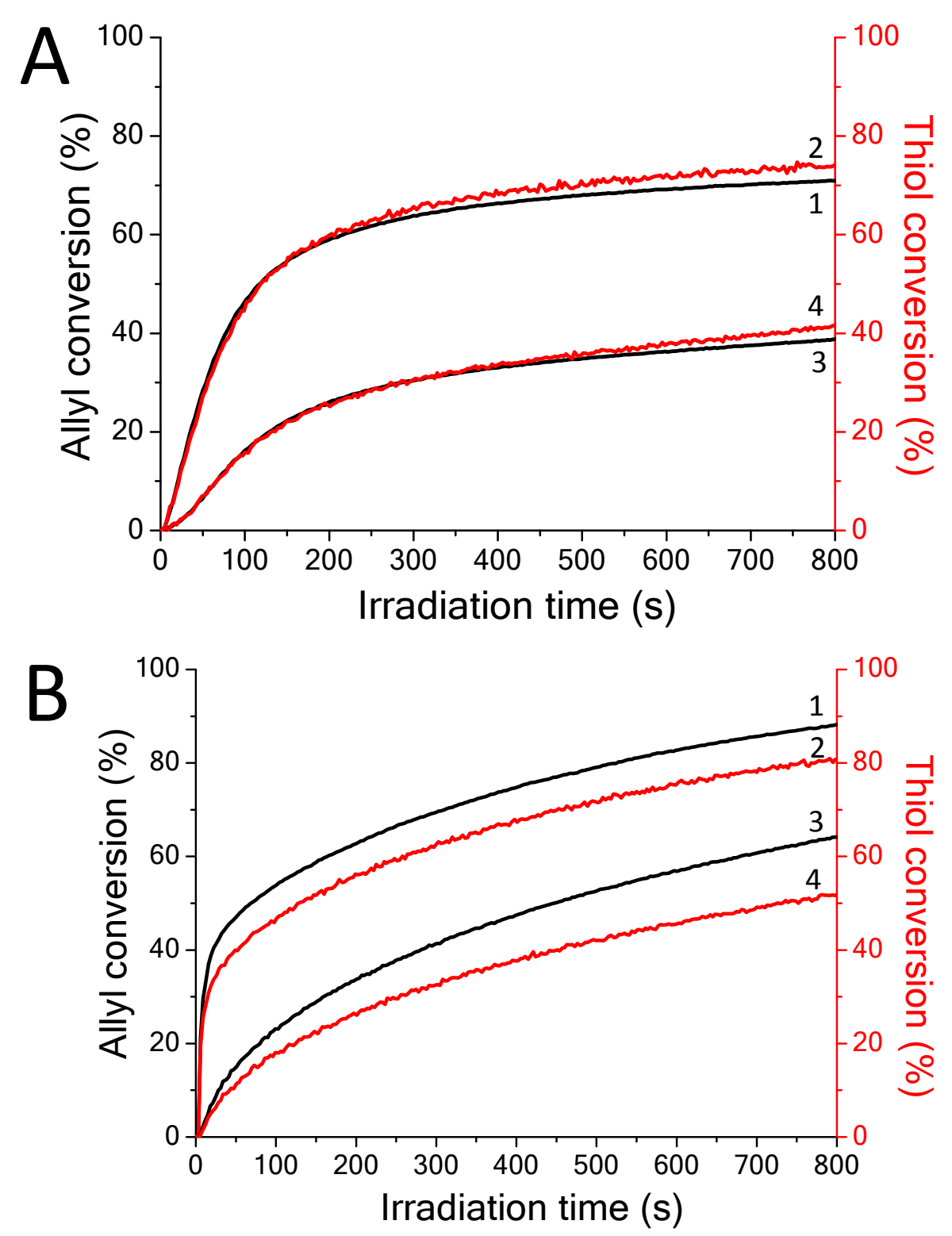

Figure S26. Kinetic profiles of the allyl and thiol functions in the DVE/trithiol formulation $(43 \% / 57 \%, \mathrm{w} / \mathrm{w})$ in the presence of A) CQ $(0.5 \mathrm{wt} \%)$ and B) CQ/Iod $(0.5 \% / 2 \%, \mathrm{w} / \mathrm{w})$ under air upon LED@455 nm (curves 1 and 2) and LED@470 nm (curves 3 and 4) exposure. Curves 1 and 3 =acrylate conversions; Curves 2 and $4=$ thiol conversions. Thickness of the film $=25 \mu \mathrm{m}$. 


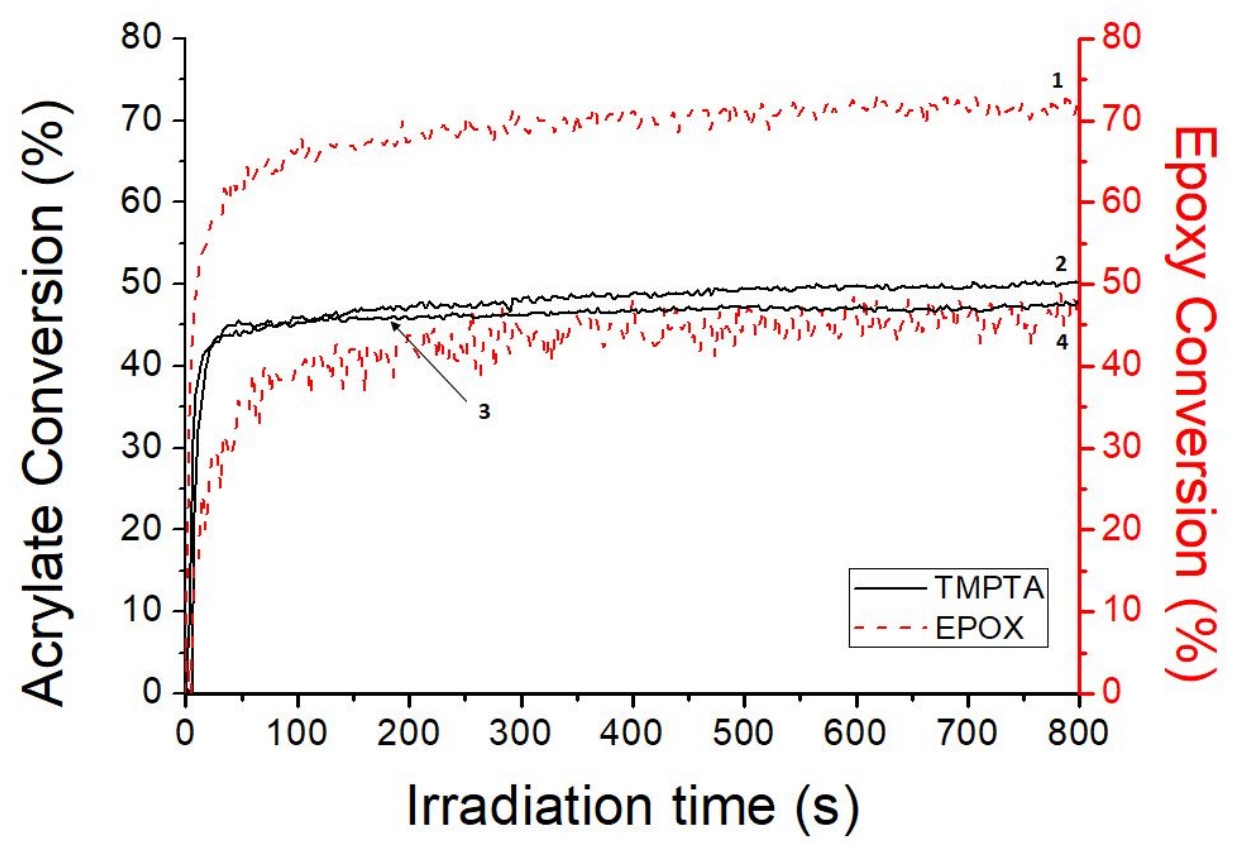

Figure S27. Photopolymerization profiles of an EPOX/TMPTA blend (50\%/50\%, w/w) under air in the presence of $\mathbf{Q A} / \operatorname{Iod}(0.5 \% / 2 \%, \mathrm{w} / \mathrm{w})(1$ and 3$)$; and in the presence of $\mathbf{Q E} / \mathrm{Iod}$ $(0.5 \% / 2 \%, w / w)$ (2 and 4) upon LED@455 nm light exposure. Curves 1 and $4=$ epoxy conversions; Curves 2 and $3=$ acrylate conversions. Thickness of the film $=25 \mu \mathrm{m}$.

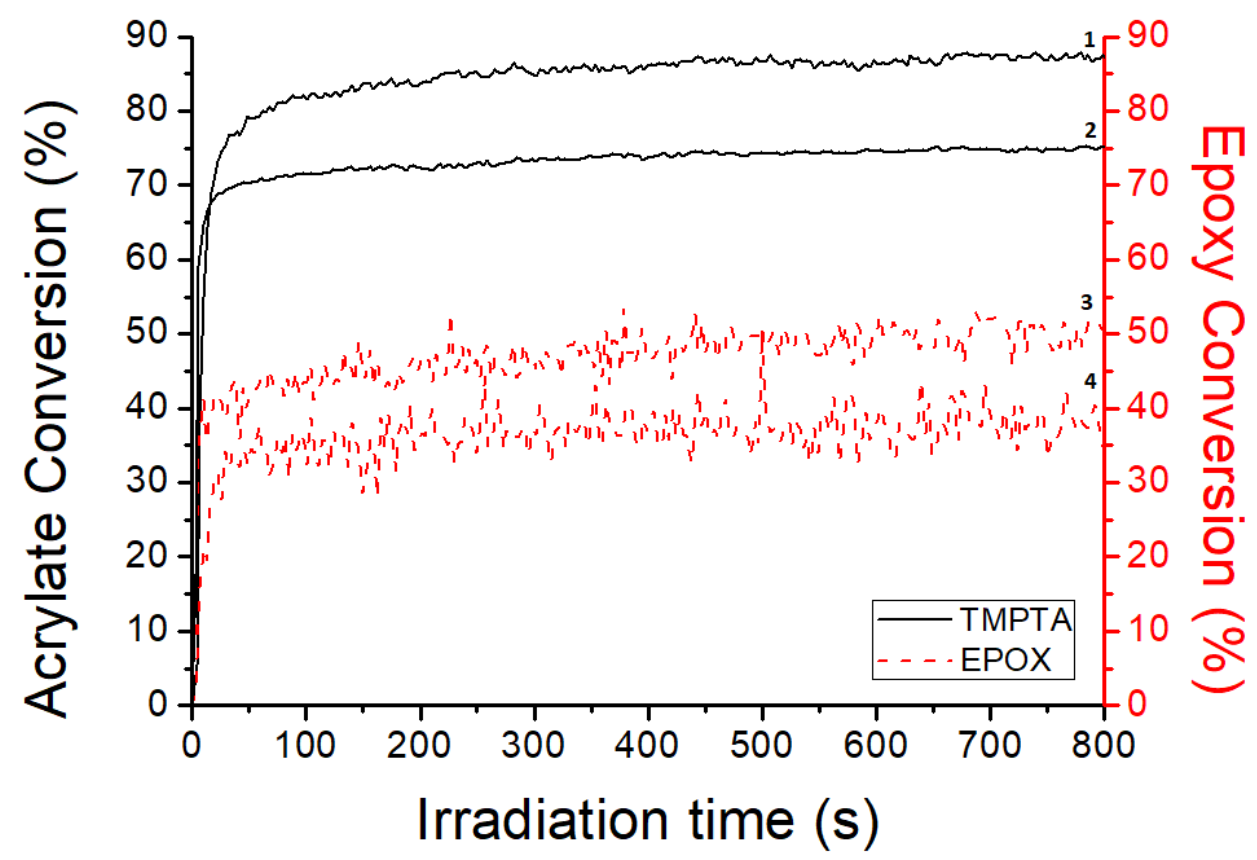

Figure S28. Photopolymerization profiles of an EPOX/TMPTA blend $(50 \% / 50 \%, \mathrm{w} / \mathrm{w})$ in laminate, in the presence of QA/Iod $(0.5 \% / 2 \%, w / w)(2$ and 3$)$; and in the presence of $\mathbf{Q E} / \mathrm{Iod}$ $(0.5 \% / 2 \%, w / w)(1$ and 4$)$ upon LED@455 nm light exposure. Curves 1 and $2=$ acrylate conversions; Curves 3 and $4=$ epoxy conversions. Thickness of the film $=25 \mu \mathrm{m}$. 

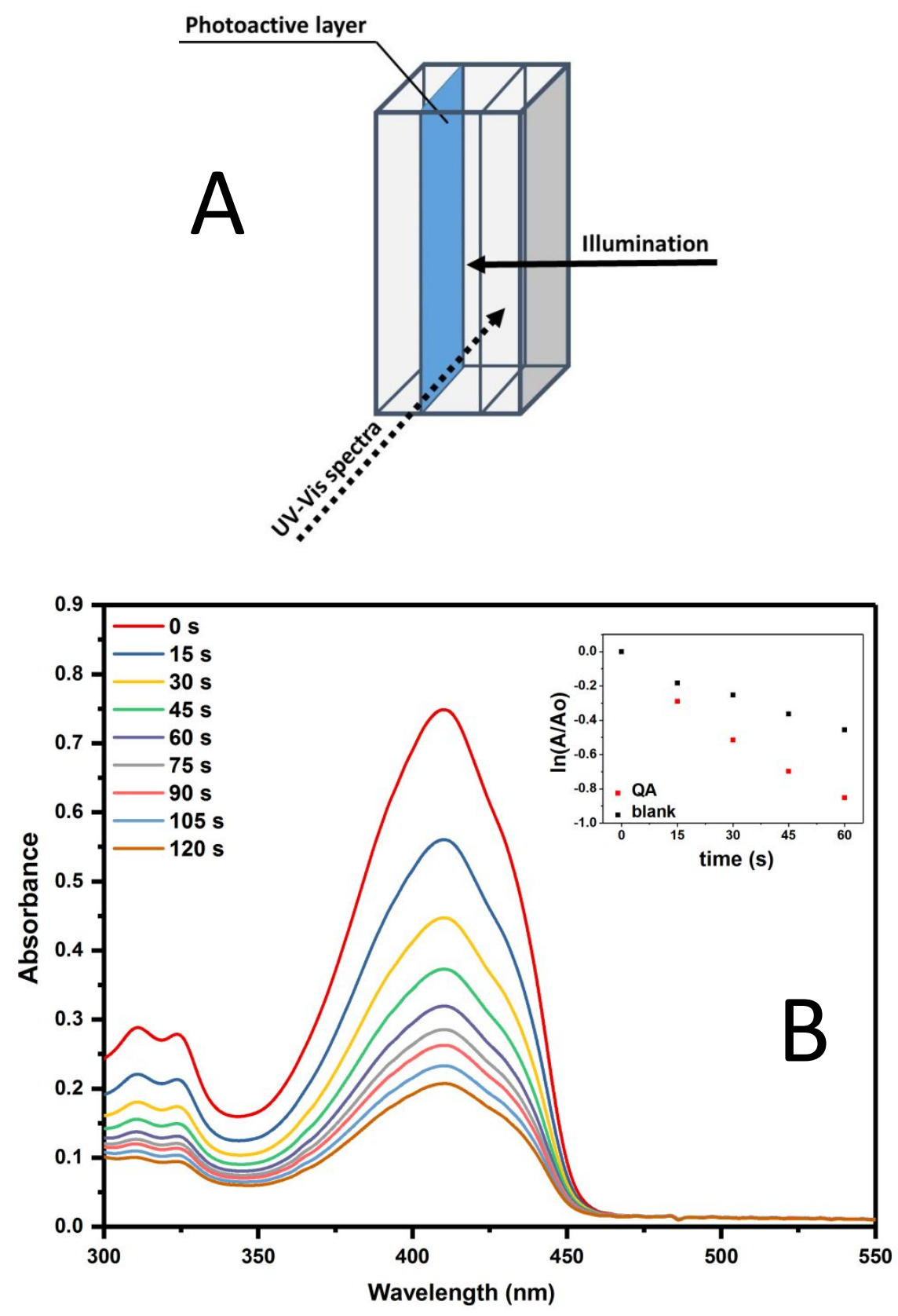

Figure S29. A) Schematic representation of the evaluation of singlet oxygen and B) UV-vis spectra of 1,3-diphenylisobenzofuran (DPBF) recorded during irradiation of QA/Iod/TMPTA/EPOX film under a Xenon lamp source. Inset: drop in the absorbance at 410 $\mathrm{nm}$ during illumination of QA/Iod/TMPTA/EPOX film with respect to the blank test. 